$$
\begin{aligned}
& \text { PFC.EIVED } \\
& \text { JAN } 27 \text { 1994 } \\
& \text { OSTI }
\end{aligned}
$$

\title{
PACKAGING AND TRANSPORTATION
}

\section{RISK MANAGEMENT AND EVALUATION PLAN}

\author{
W. R. Rhyne
}

September 1993

Prepared for

Packaging and Transportation Management Group (MAT-2)

Los Alamos National Laboratory

Prepared by

H\&R Technical Associates, Inc.

P. O. Box 4159

Oak Ridge, Tennessee 37831 


\section{TABLE OF CONTENTS}

Page

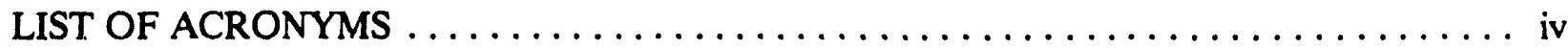

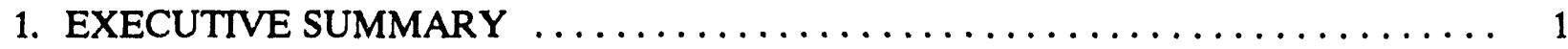

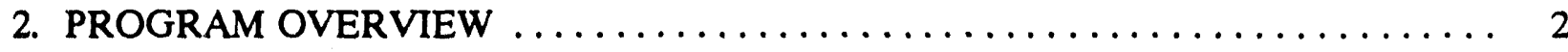

2.1 ROLE OF THE PACKAGING AND TRANSPORTATION MANUAL . . . . . 2

2.2 ROLE OF QUANTITATIVE RISK ANALYSIS $\ldots \ldots \ldots \ldots \ldots \ldots \ldots \ldots$

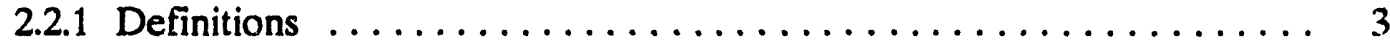

2.2.2 Potential Uses of Transportation Risk Analyses ............ 5

2.2.3 Project Scope and Objectives ..................... 8

2.2.4 Relationship to Other DOE Transportation Risk Programs ....... 8

3. TRANSPORTATION QUANTITATIVE RISK ANALYSIS $\ldots \ldots \ldots \ldots \ldots \ldots \ldots \ldots$

3.1 THE QUANTITATIVE RISK ANALYSIS (QRA) PROCEDURE $\ldots \ldots \ldots \ldots 10$

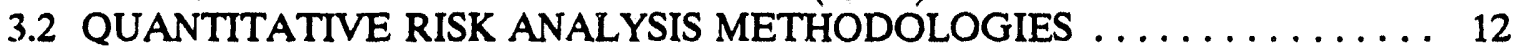

3.3 MATHEMATICAL FORMULATION $\ldots \ldots \ldots \ldots \ldots \ldots \ldots \ldots \ldots \ldots \ldots$

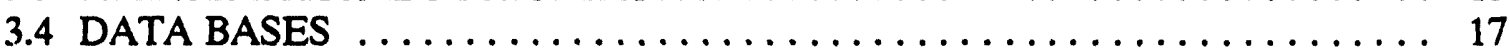

3.4.1 Accident Rate or Frequency .................... 17

3.4.2 Accident Force Types and Force Magnitudes . . . . . . . . . . . . . 19

3.4.3 Conditional Container Failure Probability ................. 22

3.4 .4 Release Amount .......................... 24

3.5 ACCIDENT SCENARIO DEVELOPMENT $\ldots \ldots \ldots \ldots \ldots \ldots \ldots \ldots \ldots$

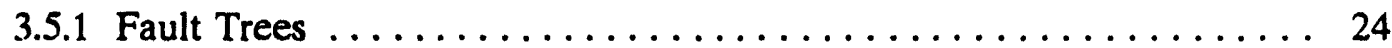

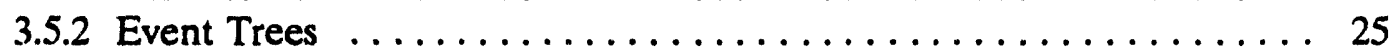

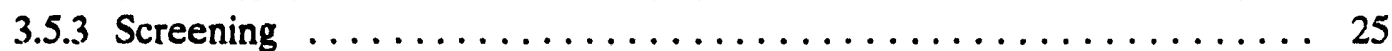

3.6 CONTAINER FAILURE THRESHOLD ESTIMATES $\ldots \ldots \ldots \ldots \ldots \ldots \ldots 28$

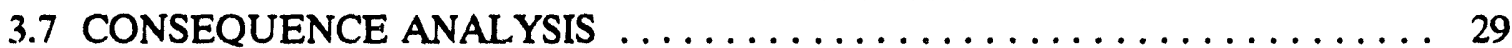

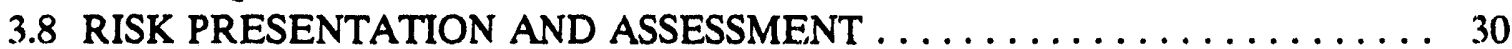

3.8 .1 Risk Acceptability . . . . . . . . . . . . . . . . . . . . . . . . 30

3.8.2 Standard Risk Presentation Methods ................... 31

3.8 .3 Uncertainty . . . . . . . . . . . . . . . . . . . . . . . 39

4. CONCLUSIONS AND RECOMMENDÄTIONS $\ldots \ldots \ldots \ldots \ldots \ldots \ldots \ldots \ldots \ldots \ldots$

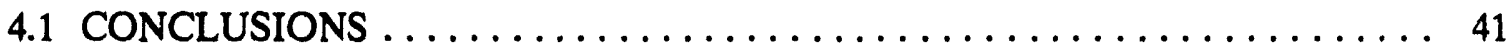

4.2 RECOMMENDATIONS $\ldots \ldots \ldots \ldots \ldots \ldots \ldots \ldots \ldots \ldots \ldots \ldots \ldots \ldots$

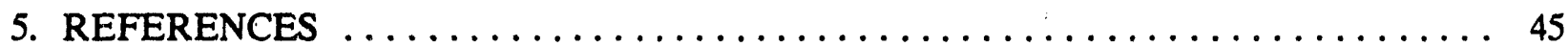

APPENDIX A EFFECT OF ROAD CLOSURE $\ldots \ldots \ldots \ldots \ldots \ldots \ldots \ldots \ldots \ldots \ldots \ldots$

APPENDIX B FAULT TREE DEVELOPMENT $\ldots \ldots \ldots \ldots \ldots \ldots \ldots \ldots \ldots \ldots$ B -1

APPENDIX $C$ EVENT TREE DEVELOPMENT $\ldots \ldots \ldots \ldots \ldots \ldots \ldots \ldots \ldots \ldots \ldots$ 


\section{LIST OF FIGURES}

Fig. $2-1$ Typicäl risk curves $\ldots \ldots \ldots \ldots \ldots \ldots \ldots \ldots \ldots \ldots \ldots \ldots \ldots \ldots \ldots$

Fig. 3-1. The quantitative risk analysis process $\ldots \ldots \ldots \ldots \ldots \ldots \ldots \ldots \ldots \ldots \ldots \ldots$

Fig. 3-2. Comparison of historical and predictive approaches $\ldots \ldots \ldots \ldots \ldots \ldots \ldots \ldots$

Fig. 3-3. Cumulative probability distribution of fire accident duration for truck transport

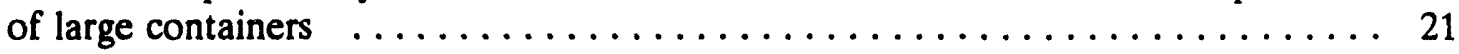

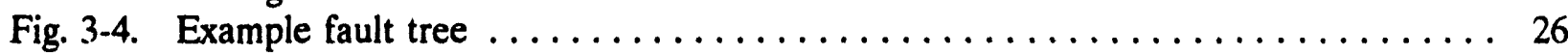

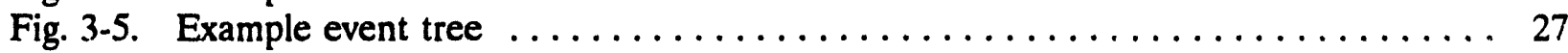

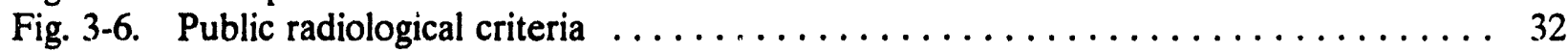

Fig. 3-7. Co-located worker radiological criteria $\ldots \ldots \ldots \ldots \ldots \ldots \ldots \ldots \ldots \ldots \ldots \ldots \ldots$

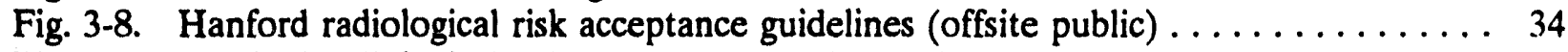

Fig. 3-9. Hanford radiological risk acceptance (onsite workers) $\ldots \ldots \ldots \ldots \ldots \ldots \ldots \ldots$

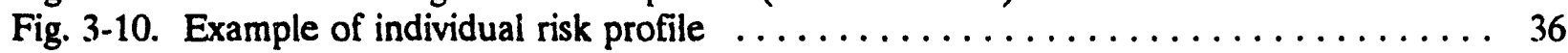

Fig. 3-11. Example of societal risk F-N curve $\ldots \ldots \ldots \ldots \ldots \ldots \ldots \ldots \ldots \ldots \ldots \ldots \ldots$

Fig. 3-12. Example of societal risk profile histogram $\ldots \ldots \ldots \ldots \ldots \ldots \ldots \ldots \ldots \ldots$

Fig. 3-13. Risk presentation incorporating management review requirements $\ldots \ldots \ldots \ldots 40$

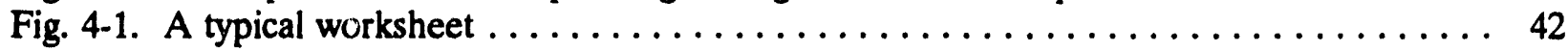

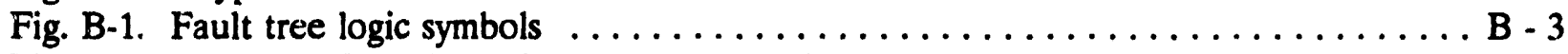

Fig. B-2. Fault tree for release from transport accident $\ldots \ldots \ldots \ldots \ldots \ldots \ldots \ldots \ldots \ldots$ B -4

Fig. B-3. Fault tree for impact force fails container $\ldots \ldots \ldots \ldots \ldots \ldots \ldots \ldots \ldots \ldots \ldots$ B -5

Fig. C-1. Simplified transportation event tree $\ldots \ldots \ldots \ldots \ldots \ldots \ldots \ldots \ldots \ldots \ldots \ldots$ C - 3

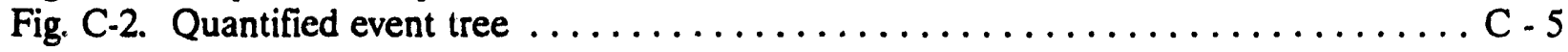

Fig. C-3. Fault trees used with the event tree $\ldots \ldots \ldots \ldots \ldots \ldots \ldots \ldots \ldots \ldots \ldots \ldots \ldots$

\section{LIST OF TABLES}

Table 3-1. Truck accident rates by state and combined $\ldots \ldots \ldots \ldots \ldots \ldots \ldots \ldots$

Table 3-2. Truck accident rates by highway type $\ldots \ldots \ldots \ldots \ldots \ldots \ldots \ldots \ldots \ldots$

Table 3-3. Distribution of FHWA-reported truck accidents by cargo type,

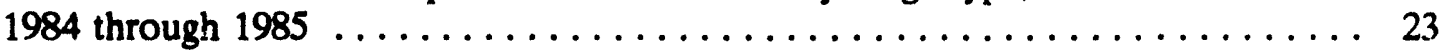

Table A-1. Partial listing of factors considered to affect truck accidents $\ldots \ldots \ldots \ldots \ldots \ldots$

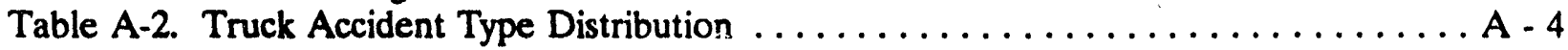




\section{LIST OF ACRONYMS}

cdf cumulative distribution function

DOE U.S. Department of Energy

DOT U.S. Department of Transportation

FHWA Federal Highway Administration

HMIS

LANL

Hazardous Material Information System

LLNL

NRC

OTA

PHA

Plan

PTM

QRA

RSPA

SNL

Los Alamos National Laboratory

Lawrence Livermore National Laboratory

U.S. Nuclear Regulatory Commission

Office of Technology Assessment

preliminary hazards analysis

the present report

Packing and Transportation Manual

quantitative risk analysis

Workbook

Research and Special Programs Administration

Sandia National Laboratories

a MAT-2 risk management tool consisting of worksheets 


\section{EXECUTTVE SUMMARY}

Shipments of radioactive materials and hazardous chemicals at the Los Alamos National Laboratory (LANL) are governed by a variety of Federal and state regulations, industrial standards, and LANL processes and procedures. Good judgement is exercised in situations that are not covered by regulations. As a result, the safety record for transporting hazardous materials at LANL has been excellent. However, future decisions should be made such that the decisionmaking process produces a defensible record of the safety of onsite shipments. This report proposes the development of a risk management tool to meet this need.

First, the application of quantitative risk analysis methodology to transportation is presented to provide a framework of understanding. Risk analysis definitions, the basic quantitative risk analysis procedure, quantitative methodologies, transportation data bases, and risk presentation techniques are described. Quantitative risk analysis is frequently complex; but simplified approaches can be used as a management tool to make good decisions.

Second, a plan to apply the use of risk managemen* principles to the selection of routes, special administrative controls, and containers for hazardous nisterial transportation at LANL is provided. A risk management tool is proposed that can be used by MAT-2 without substantial support from specialized safety and risk analysis personnel, e.g., HS-3. A workbook approach is proposed that can be automated at a later date.

The safety of some types of onsite shipments at LANL is not well documented. Documenting that shipments are safe, i.e., present acceptable risks, will likely require elaborate analyses that should be thoroughly reviewed by safety and risk professionals. These detailed analyses are used as benchmarks and as examples for the use of the proposed tool by MAT-2. Once the benchmarks are established, the workbook can be used by MAT-2 to quantify that safety goals are met by similar shipments. The need, or lack of a need, for special administrative controls can be determined using the proposed risk management tool. Selection of the route that minimizes risk is also a straightforward application of the proposed risk management tool. 


\section{PROGRAM OVERVIEW}

\section{ROLE OF THE PACKAGING AND TRANSPORTATION MANUAL}

The LANL Packaging and Transportation Manual (PTM) is currently under development (LANL 1993a). The PTM will be the governing document for onsite, offsite, and intralaboratory shipments and will be supported by safety documentation, procedures, QA documentation (LANL, 1993b), etc. as necessary. The PTM will address the complete range of the LANL packaging and transportation program, including, but not limited to, the following subjects.

(1) Identification of the packaging and transportation process, functions, and responsibilities. The responsibilities of MAT-2, the shipping organization, oversight organizations, and other organizations will be explained within the framework of the LANL site organization. Responsibilities, lines of authority, and approval procedures will be clearly described. Key positions within these organizations will be identified so that the program and process are understood.

(2) Regulations that are imposed by organizations external to LANL will be identified. Government and industrial standards will be referenced. Site-specific standards, requirements, and procedures will be presented. The site-specific requirements will address securing of loads, load compatibility, radiation exposure control, criticality control, etc. In some cases, procedures applicable to all transport or to transport of a class of materials or containers will be appropriate. In many cases, however, container-specific loading and securing procedures will be needed. All types of transportation will be addressed including onsite and offsite; chemical, explosive, and radioactive materials; and routine and nonroutine shipment.

(3) Personnel qualification and training, record keeping, incident reporting, vehicle and container maintenance, and emergency response will be addressed in the PTM. 
(4) The safety documentation and risk management aspects of all types of shipments will be addressed. (Training, emergency response, QA, etc. are all part of the normal safety baseline and are not addressed explicitly in the safety portion of the PTM.) The safety philosophy and approach are first presented, e.g., the need for containment, communication, and control commensurate with the hazards. Safety documentation for each container routinely used will describe the types of transport situations in which the container may be used without additional analysis and approval. Included in the documentation are allowable types and amounts of materials that can be transported; references to loading, unloading, tie-down, and other procedures; references to maintenance requirements; and so forth. If the container is certified by the U.S. Department of Transportation (DOT) or the U.S. Department of Energy (DOE), then the safety documentation will not address the adequacy of the container design in depth. Special controls required to achieve an acceptable level of safety will be described and defended in the container documentation. The PTM will also address the procedure for approval of nonroutine shipments.

This Plan addresses how quantitative risk assessment can be used as a risk management tool to demonstrate an acceptable level of safety for onsite shipments.

\subsection{ROLE OF QUANTTTATIVE RISK ANALYSIS}

The objective of this Plan is to propose a methodology for using risk analysis principles as a decision tool for managing packaging and transportation activities at LANL. In the subsections that follow, risk analysis terms are first defined. Some potential uses of transportation risk analysis at LANL are then presented. Last, the scope and objectives of this project are discussed.

\subsubsection{Definitions}

The terms hazard and risk are synonymous in ordinary language but are quite different in technical language. A bazard is the inherent characteristic of a material, condition, or activity that has the potential to cause harm to people, property, or the environment. A tank pressurized with 
air has the potential to cause harm to people from fragments should the tank fail. An unpressurized tank filled with a toxic material has the potential to cause harm because of the quantity of toxic material that could be released.

Risk is the combination of the likelihood and the consequence of a specified hazard being realized. Likelihood can either be expressed as a frequency or a probability. In this report, likelihood will generally be expressed as a frequency. Frequency is the rate at which events occur and may be expressed as events/year, accidents/mile, etc. The frequency component of risk often consists of the basic frequency multiplied by several conditional probability terms. Probability is a number between 0 and 1 that expresses a degree of belief concerning the possible occurrence of an event. In this report, the term probability usually refers to a conditional probability. A conditional probability is a probability for an event that has been preceded by another specified event. Consequence is the direct effect, usually undesirable, of the accident or incident. Consequences are usually measured in health effects but may be expressed as cost of property loss or the amount of hazardous material released.

Many times, risk is defined as frequency times consequence. This expression is a subset of the risk definition presented earlier. When frequency (or probability) is multiplied by consequence, an accident that is expected to cause 1 fatality and occur 10 times a year has the same mathematical risk as an accident that is expected to cause 1000 fatalities and occur once every 100 years. As can be seen, a great deal of information may be lost when risk is expressed as the product of frequency and consequence.

A quantitative risk analysis incorporates numerical estimates of frequency and consequences in a sophisticated but approximate manner. In practice, few decisions require quantification at equal levels of sophistication of both frequency and consequence. An absolute or complete quantitative risk analysis incorporates quantitative estimates of both frequency and consequence and the consequences are expressed to the full extent, i.e., to health effects. The advantage of an absolute risk analysis is that it could be used to show that the process is safe, i.e., the calculated risk meets some acceptable risk criteria. The disadvantages of absolute estimates are, first, that certainty about the accuracy of the results is impossible. Second, no standard risk acceptability criteria exist. Third, the numerical estimates are difficult for nonexperts to interpret (Arendt et al. 1989). 
A relative risk analysis means that a risk is evaluated in comparison with another risk. The comparison can be qualitative or quantitative. (An example of a quantitative comparison is "the risk of option $\mathrm{A}$ is 3.2 times higher than the risk of option B." An example of a qualitative comparison is "the risk of option $A$ is much higher than the risk of option B.") Relative risk estimates have the advantage of being much less likely to be misinterpreted and the accuracy of the results is easier to defend. The results can be used to rank risk reduction measures. The primary disadvantage is that the results show only that one option is less risky than another but do not indicate whether one, both, or neither option is acceptable (Arendt et al. 1989).

The terms, risk assessment and risk analysis are usually used interchangeably. The author prefers to define risk analysis as the computation of risks and risk assessment as the determination of risk acceptability, perhaps by comparison of results with other risks.

An initiating event is the first in a sequence of events that may lead to an undesirable consequence. An example is the failure of truck brakes to function. If an accident results, contributing factors could be excessive speed, poor visibility, etc. In transportation risk analysis, the initiating event is usually considered a reportable accident, an accident that is of sufficient severity to require notification of regulatory bodies. The minimum reportable accident is defined by state or federal regulatory bodies on the basis of the level of property damage or whether an injury or death occurs.

A reportable accident does not necessarily involve the release of the hazardous material being transported. The DOT defines an incident as a release occurring during loading, unloading, while the vehicle is enroute, or when it is in temporary storage related to transportation. Thus, an incident may be unrelated to an accident or may arise from an accident. An accident may or may not result in an incident. In this report we are only interested in accidents that cause a release.

\subsubsection{Potential Uses of Transportation Risk Analyses}

Transportation regulations are not based on quantitative risk analyses, and they do not require that a risk analysis be performed. Transportation risk analysis can, however, provide quantitative answers to important questions about hazardous materials packaging and transportation at LANL. Further, transportation risk analyses can support rational, defensible allocation of resources. 
The DOT has set standards or specifications for containers that are used for transporting hazardous materials such as chemicals, explosives, and less-than-Type B quantities of radioactive materials. Container requirements for Type B quantities of radioactive materials are specified by the U.S. Nuclear Regulatory Commission (NRC). Offsite shipments are required to be in compliance with applicable regulations. Onsite shipments are not always in containers approved by DOT, NRC, or DOE. Chemicals are not produced at LANL; rather, they are received from offsite vendors in DOT-approved containers. Subsequent onsite transport is generally in the original container; therefore, onsite shipment of chemicals is not usually an issue at LANL. Radioactive materials are produced at LANL and their onsite transport has occurred for many years. The issue at LANL is the documentation of the safety of this transport. Throughout this report, onsite transport will generally imply radioactive material transport. The methodology is also applicable to the transport of explosives or hazardous chemicals.

An absolute risk analysis is needed to show that the use of a specific container, materials, route, and set of procedures is safe. In some cases, the required analysis may be complex and expensive. Direct comparison of risk calculations to the regulations suffers from the absence of a probabilistic basis for the regulations; therefore, a criterion to judge the acceptability of a calculated risk level is needed for this type of analysis. An acceptable risk criterion and a computed risk curve are illustrated in Fig. 2-1. Note that the computed risk gives a lower consequence for the same frequency than does the acceptable risk, and for a given consequence, the computed frequency is less than the acceptable risk criterion. Thus, the computed risk shown in Fig. $2-1$ is acceptable.

Good risk decisions can be based on a relative risk basis, that is, option $\mathrm{A}$ is twice as risky as option B. Given that some detailed absolute risk analyses have been prepared, a less extensive relative risk analysis can be used to show thai a somewhat different transport situation is also safe. A different material type or shape in an otherwise approved container is an example of a candidate for a relative risk analysis.

If a container is known to have less structural capability than that required for certification, a relative risk analysis can show quantitatively that special procedures such as temporary road closure in fact produce a release probability equivalent to the use of a certified cask. 


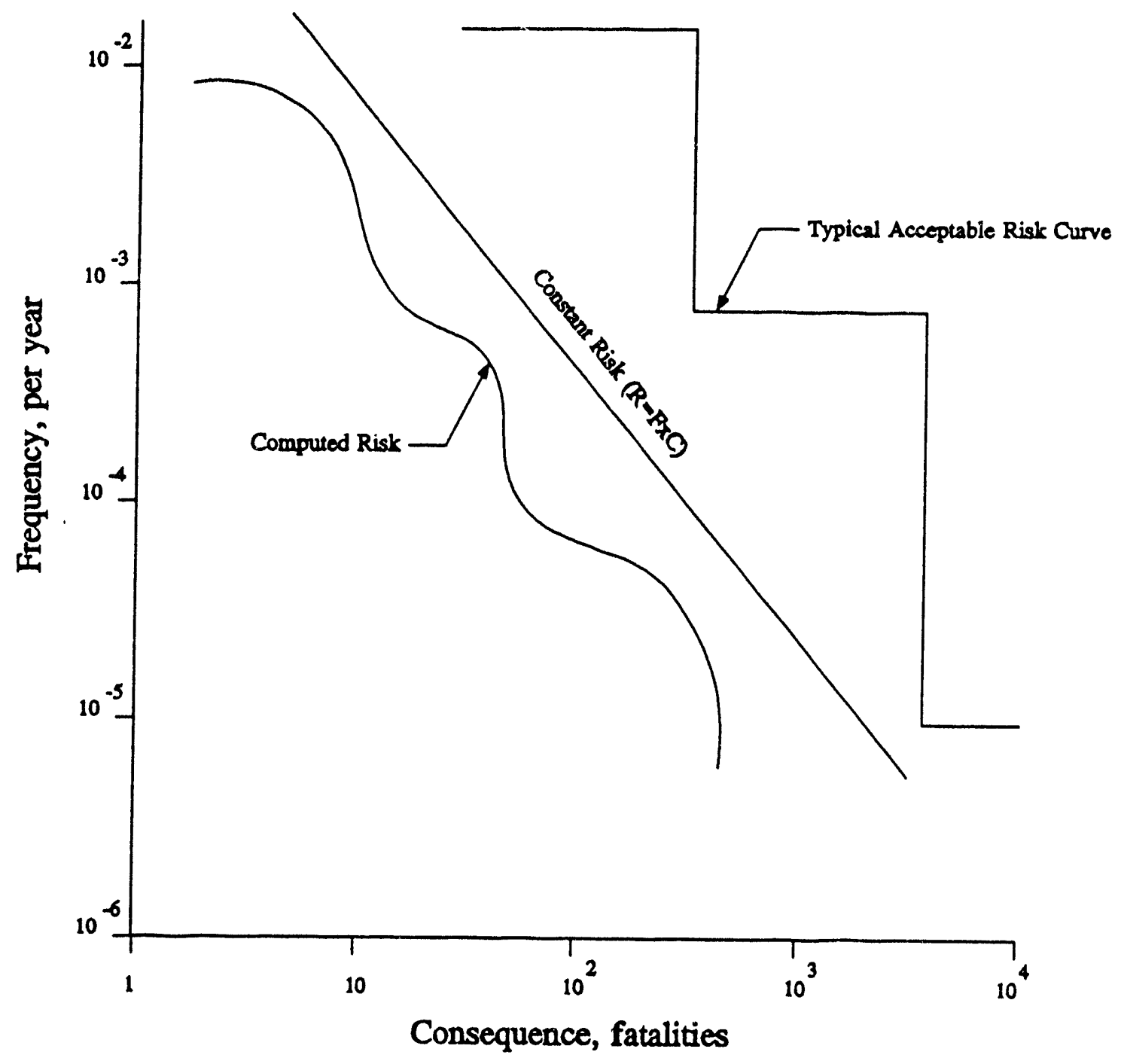

Fig. 2-1. Typical risk curves 


\subsection{Project Scope and Objectives}

The primary emphasis of this project is the analysis of the safety of onsite use of noncertified containers. The ultimate objective is to develop a user-friendly tool for MAT-2 to use in applying risk management principles to the selection of routes, special administrative controls, and containers. The tool will also provide a quantitative record that onsite transport is safe. The present report (and contract) presents a plan (referred to as the Plan) for developing the risk management tool; the detailed development and application of the tool will take place under a separate contract.

H\&R's suggested approach is to develop a risk management calculational tool in a workbook format (referred to as the Workbook). This format facilitates later automation.

Transport of radioactive materials produces two types of risk: accident risk and nonaccident risk. The nonaccident risk component is due to the radiation level that exists even if DOT radiation dose level requirements are met and no accidents occur. It is assumed in this report that all shipments are in conformance with DOT requirements for dose level at the container surface and vicinity. Furthermore, it is assumed that the risk due to receiving the small dose allowed by the regulations is not an issue.

Criticality is assumed to be addressed for both accident and nonaccident conditions by administrative controls other than this risk management tool.

\subsubsection{Relationship to Other DOE Transportation Risk Programs}

The RADTRAN computer code was originally developed from 1975 to 1977 by Sandia National Laboratories for NRC. Subsequent versions have been funded by DOE; the current version is RADTRAN 4 (Newhauser and Kanipe, 1992). RADTRAN is a large, multipurpose code that addresses transport of radioactive materials by several truck options, rail, barge, ship, and two air options. A large amount of input data is needed and a large amount of output is generated. RADTRAN can be used to select routes, but it is very cumbersome for this application at LANL. The container failure probabilities and associated release fractions must be input as a function of accident severity categories; therefore, RADTRAN is no help with this complex problem unless the default data for typical certified containers apply to a specific shipment at LANL. 
RADTRAN was originally developed to study risks on a programmatic basis from broadly defined categories of waste types. Current usage is primarily to demonstrate the low risk of spent fuel shipment in certified casks for selected routes across the United States. RADTRAN's use for LANL traffic management purposes would be gross overkill. The applicable RADTRAN data and models will be extracted and put into the user friendly, LANL-specific Workbook.

A program has been instituted at Lawrence Livermore National Laboratory (LLNL) to evaluate transportation risks from highway shipments made under DOE Order 5610.1 (Sandquist, et al. 1992). Cross country routes are modeled in detail, and the doses from airborne, surface water, direct radiation, groundwater, and the food chain are modeled in detail. The level of detail is gross overkill for LANL traffic management applications. If access can be gained to LLNL modeling of explosives, tritium, etc., then some benefit is likely for the proposed Workbook. The information is likely classified; therefore, LANL would need to approach Defense Programs to establish the need to know.

Other DOE sites are working on onsite transportation risk documentation. Westinghouse Hanford is looking at onsite quantitative risk analysis, motor carrier evaluation, and possibly other areas. Westinghouse Savannah River has used probabilistic methods to evaluate the safety of some specific movements. Several years ago, Martin Marietta Energy Systems in Oak Ridge was planning to survey onsite safety methodologies across the DOE sites for DOE Headquarters. The results or status are not known to the author. It is suggested that MAT-2 develop networks with other sites to avoid duplication of effort. 


\section{TRANSPORTATION QUANTITATIVE RISK ANALYSIS}

\subsection{THE QUANTTTATTVE RISK ANALYSIS (QRA) PROCEDURE}

The QRA procedure is basically the same for transportation as for process system risk analysis. Five basic steps are defined, each of which consists of several substeps as shown in Fig. 3-1.

Preliminary hazards analysis

The first activity in a QRA is frequently called a preliminary hazards analysis (PHA). The first step in a PHA is to define the objectives, scope, and other bounds of the analysis. A question can be asked to help define the analysis: "Why is this analysis being done?" That is, "What decision(s) is to be made by using the results of this analysis?" The decision(s) to be made will affect the type of analysis. Several types of analyses useful to LANL were described in Section 2.2.2 and further details are given in Section 4.

For enroute analyses, the hazard identification is straightforward: the hazard is the hazardous material being transported. Loading and unloading and other facets of the use of the material being transported may be in the analysis scope. In such a case, hazards can arise from nearby materials or processes that may affect the material being loaded or unloaded.

The analysis objectives need to be considered when selecting the consequences to be evaluated. If a relative risk evaluation of routing alternatives is needed, then the consequence reduces to the number of persons exposed (see Section 3.3). The very detailed analyses described in Section 2.2.4 are not likely needed for most LANL analyses.

The initiating event is the accident.

\section{Accident scenario development}

The accident scenario considers the accident initiator, forces that arise from the accident, and how the container reacts to the forces. The two primary techniques for developing transportation accident scenarios are fault trees and event trees. Accident scenario development can be standardized for most LANL analyses. (See Section 3.5.) 
PRELIMINARY HAZARDS ANALYSIS

Define objectives, scope, and level of effort Identify hazards

Determine consequences of interest

Identify initiating events

\section{ACCIDENT SCENARIO DEVELOPMENT}

Identify accident forces

Evaluate failure modes

\section{FREQUENCY ANALYSIS}

Evaluate initiator frequency

Estimate conditional probability of a release

Determine conditional probabilities for consequence analysis

\section{CONSEQUENCE ANALYSIS}

Characterize source term

Quantify exposure and effect

Estimate population exposed

\section{KISK EVALUATION}

Estimate risks

Identify major contributors

Define/evaluate risk reduction alternatives

Document analysis

Source: Rhyne In Press

Fig. 3-1. The quantitative risk analysis process 


\section{Frequency analysis}

The frequency analysis consists of determining not only the frequency of the accident initiator (the truck accident), but also other factors directly affecting the release scenario, e.g., the probability of a fire, given an accident. Methods and data for determining these probabilities are presented in Sections 3.3 and 3.4.

\section{Consequence/Analysis}

Consequence analysis tools for transportation accident scenarios are the same as those used for stationary process plant analysis. Many different physical processes must be evaluated to envelope all hazardous materials shipments at LANL. For the majority of the shipments of interest, the consequence calculations can be standardized.

\section{Risk evaluation and presentation}

Risk evaluation and presentation methods are the same for transportation and process risk analyses. An overview of risk presentation approaches is contained in Section 3.8.

\subsection{QUANTITATTVE RISK ANALYSIS METHODOLOGIES}

Risk has been defined in terms of two parameters: the likelihood (frequency or probability) of the occurrence of an accident scenario and the magnitude of the accident consequence. QRA methodologies for transportation can be grouped by the level of detail and the data sources/modeling approach. The highest level of detail occurs in the "bottom-up" approach, which begins at the smallest risk component and progresses upward by combining results to obtain an overall risk. In contrast, other applications start at a high level of data aggregation, i.e., low level of risk component detail. The use of fault trees and event trees is considered one end of the data/modeling scale and an average release rate is considered at the other end of the scale. The bottom-up approach to data/modeling is consistent with a high level of data and modeling complexity, and the top-down approach is consistent with a high level of data aggregation. Rowe (1983) describes bottom-up as a "fine-grain" estimate made up of a large 
number of computations and "top-down" as the aggregation of data to find "cause and effect relationships that can then be used to find overall values" for conditional probabilities. As pointed out by Rowe, there are difficulties in obtaining data for use of either the top-down or the bottom-up approach, particularly for an absolute risk analysis.

All quantitative risk analyses aggregate risk-producing components to some level. Before considering this characterization of risk methodology further, the two parameters, frequency and consequence, must be defined in more detail.

The frequency component of risk can be considered as consisting of three subcomponents: the accident frequency, the conditional probability of the release of contents given that an accident has occurred, and conditional probabilities that arise from the consequence component such as the meteorological conditions. The consequence component of risk can be considered to consist of three subcomponents: the amount of material released, the number of people exposed, and the health effect(s) of the exposure. These six subcomponents are frequently further divided.

The way these parameters are evaluated depends on the risk analysis methodology being used. In most cases data are not exact for the specific situation. If the risk analyst compensates for lack of specific data by using data for a broad class of situations, for example, failure probability for radioactive material containers in general, then the approach is said to be historical. If engineering models are used, the approach is said to be predictive.

This choice of approach illustrates the two broad classes of quantitative transportation risk analysis: predictive and historical. Generally the predictive approach is synonymous with the bottom-up method and the historical with the top-down method. The choice between the predictive and historical approaches is illustrated in Fig. 3-2. If data are available that apply directly to the situation, then they should be used. However, if the data are not applicable, the analyst using the predictive approach would use engineering models and available data to construct an approximation for the needed parameter from the bottom-up. The analyst using the historical approach would broaden the definition of the hazardous material to include other materials of similar behavior, or broaden the definition of the container to include other similar containers, etc., until enough historical data are included in the definition to permit derivation of a statistically significant value for the needed parameter. That is, the historical analysis proceeds from the top down until enough data are aggregated. In practice some parameters are almost 


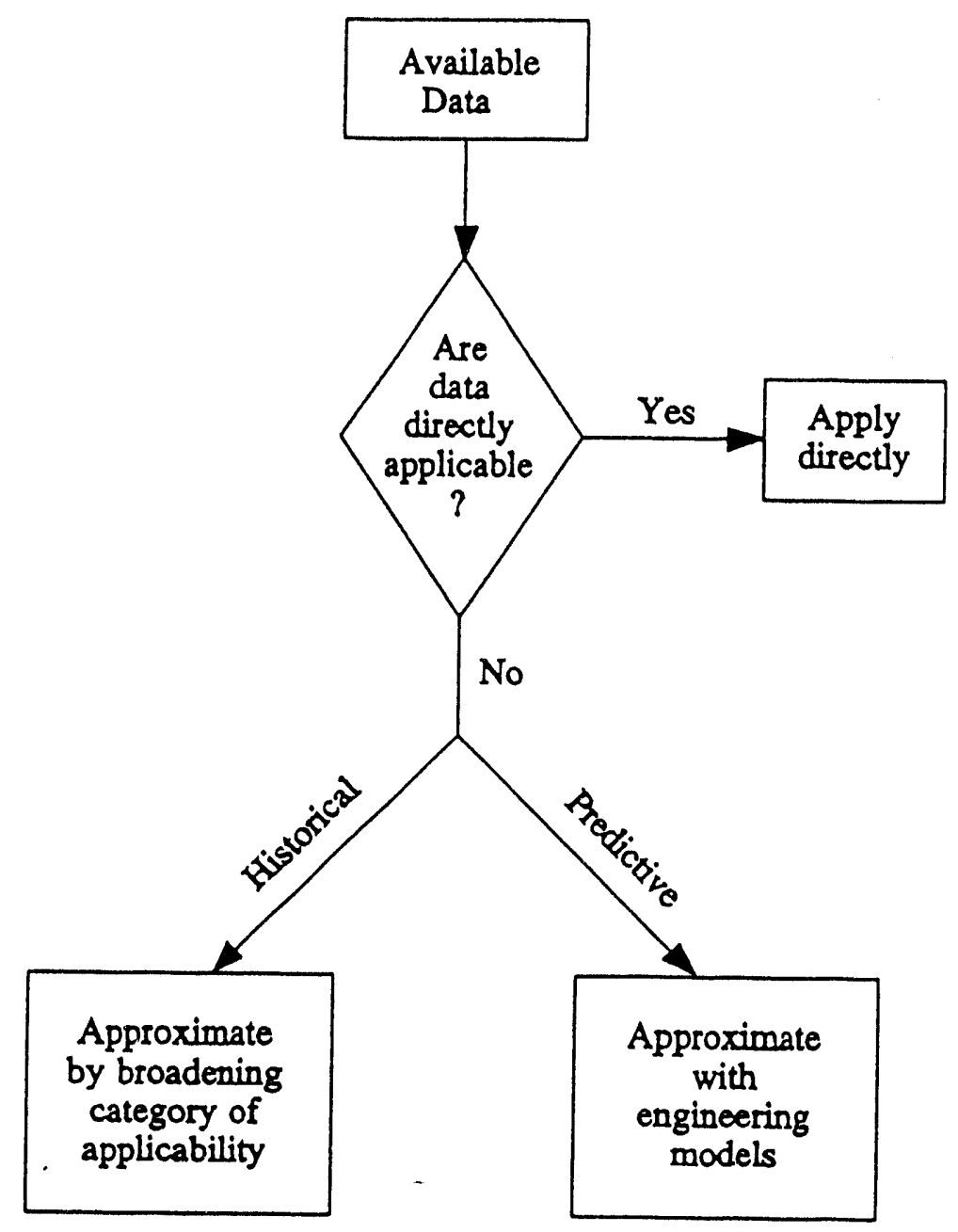

Source: Rhyne In Press

Fig. 3-2. Comparison of historical and predictive approaches 
always evaluated using historical data, e.g., accident rate. The distinction rests on how other parameters are evaluated, particularly container failure probability. The more computational complex predictive or bottom-up approach to quantitative risk analysis is appropriate for LANL situations because a sufficient data base for radioactive material containers in accidents is not available.

\subsection{MATHEMATICAL FORMULATION}

The risk, $R_{i}$, for accident scenario $i$ is a function of the scenario frequency, $F_{i}$, and the scenario consequence, $C_{i}$ :

$$
R_{1}=f\left(F_{i}, C_{i}\right)
$$

The usual procedure for a quantitative transportation risk analysis is to divide the transport route into segments (also called links) along which the important parameters can be reasonably approximated by a single average value. A detailed expression for risk can then be further defined:

$$
R_{1}=f\left(F_{1 a} \times M_{2} \times P_{2 a b} \times P_{3 a b c} \times P_{4 a d} \times P_{5 a b}, N_{a d} \times A_{a b c} \times X_{a c o}\right)
$$

where

$$
\begin{aligned}
& F_{1 \mathrm{a}} \quad=\quad \text { frequency of an accident per mile in transport link } a \text { based primarily on } \\
& \text { highway (or rail track) type and conditions, vehicle type, and traffic } \\
& \text { conditions; } \\
& \mathrm{M}_{\mathrm{a}} \quad \text { = number of miles, or miles per year, in link } a \text {; } \\
& \mathrm{P}_{2 \mathrm{ab}}=\text { probability that the accident in link } a \text { results in accident forces of type } b \\
& \text { (e.g., mechanical or thermal forces); } \\
& \mathrm{P}_{3 a b c}=\text { probability that release class } c \text { occurs, given that the accident force type } b \\
& \text { occurs in link } a \text {, which depends on the force magnitude and the container's } \\
& \text { capability to resist the force; } \\
& \mathrm{P}_{\text {tad }}=\text { probability that population distribution class } d \text { occurs in link } a \text {; } \\
& \mathrm{P}_{\text {Sae }}=\text { probability that meteorological condition } e \text { occurs in link } a \text {; } \\
& \mathrm{N}_{\mathrm{ad}}=\text { number of persons in affected area } d \text { in link } a \text {; }
\end{aligned}
$$




$$
\begin{aligned}
\mathrm{A}_{\mathrm{abc}}= & \text { release amount for release class } c, \text { given that force type } b \text { occurs in link } a \\
\mathrm{X}_{\mathrm{ace}}= & \text { fraction of persons in the affected area which experience the specified } \\
& =\begin{array}{l}
\text { health effect from a unit release of the hazardous material for } \\
\text { meteorological condition } e \text { for release class } c .
\end{array}
\end{aligned}
$$

The overall risk is obtained by summing all scenarios for each link or for the entire route:

$$
R=\sum R_{\mathbf{Y}}
$$

Equation (3-2) will produce a quantitative value for absolute (or complete) risk. It is frequently useful to compute relative risk for two or more options using only a few of the parameters from Eq. (3-2) as a surrogate for risk. This approach is used frequently for comparing routing options. Historically, the basic approach has been to use the accident rate per mile times the number of miles in a highway segment as a surrogate for the frequency portion of Eq. (3-2) and the number of people in a 0.5 -to 1 -mile-wide band along the highway segment as a surrogate for the consequence portion of Eq. (3-2). The product of the two terms is a relative risk indicator, and the route with the lowest indicator has the lowest computed relative risk.

Expressing the relative risk indicator approach mathematically will be helpful in Section 4. For simplicity of presentation, the following assumptions will be used: only one release class $(c=1)$, one population distribution along each link type $(d=1)$, and one meteorological condition $(e=1)$. Thus, $P_{4}=P_{5}=1$. If comparison of the relative risk of options $x$ and $y$ is desired, then the question is whether $R^{x}$ is less than, greater than, or equal to $R^{y}$. Using Eq. (3-2), the question can be reformulated as follows:

$$
\text { Compare } F_{1}^{x} M^{x} P_{2}^{x} P_{3}^{x} A^{x} X^{x} N^{x} \text { and } F_{1}^{y} M^{y} P_{2}^{y} P_{3}^{y} A^{y} X^{y} N^{y} \text {. }
$$

If some terms are the same for both options, as would be the case for many routing studies (e.g., if $\mathrm{P}_{2}^{\mathrm{x}}=\mathrm{P}_{2}{ }_{2}, \mathrm{P}_{3}^{\mathrm{x}}=\mathrm{P}_{3}, \mathrm{~A}^{\mathrm{x}}=\mathrm{A}^{\mathrm{y}}$, and $\mathrm{X}^{\mathrm{x}}=\mathrm{X}^{\mathrm{y}}$ ), then Eq. (3-4) is simplified to the following expression for routing purposes: 


$$
\text { Compare } F_{1}^{x} M^{x} N^{x} \text { and } F_{1}^{y} M^{y} N^{y} \text {. }
$$

Other uses of Eq. (3-4) will be described in Section 4.

\subsection{DATA BASES}

\subsubsection{Accident Rate or Frequency}

The accident rate is the number of accidents per unit of highway length. This is expressed as

$$
\text { accident rate (accidents } / \text { mile) }=\frac{\text { number of vehicle accidents }}{\text { number of vehicle miles }} .
$$

The accident rate is computed by dividing the number of accidents that have occurred by the corresponding exposure measure of opportunities for an accident to occur, i.e., number of vehicle miles. Data are available for both the number of accidents and the number of vehicle miles; however, collection procedures and quality vary.

Use of one of the existing analyses of the various data bases for both the numerator and the denominator is quick and inexpensive and should result in values that are reasonably accurate. Since at least the early 1980s, it has been known that the truck accident rate varies with road type and with population density. The most widely referenced values (Harwood and Russell 1990) are shown in Table 3-1. A set of values that are consistent with Table 3-1 and are aggregated in a way that is sometimes useful is presented in Table 3-2 (Jovanis et al. 1989). Each LANL route will be examined as part of the Workbook development to establish which discriptor from Tables 3-1 and 3-2 is the most applicable and which associated accident rate to apply to the route or portion of the route.

The accident rate can be reduced by a factor of 12 for LANL highways when the road is temporarily closed. This value is derived in Appendix A. 
Table 3-1. Truck accident rates by state and combined

\begin{tabular}{||c|c|c||}
\hline \multicolumn{2}{|c|}{ Highway Class } & \multirow{2}{*}{$\begin{array}{c}\text { Truck Accident Rate } \\
\text { (accidents per mile) }\end{array}$} \\
\hline Area Type & Roadway Type & $2.19 \times 10^{-6}$ \\
\hline Rural & Two-lane & $4.49 \times 10^{-6}$ \\
\hline Rural & Multilane undivided & $2.15 \times 10^{-6}$ \\
\hline Rural & Multilane divided & $0.64 \times 10^{-6}$ \\
\hline Rural & Freeway & $8.66 \times 10^{-6}$ \\
\hline I'ban & Two-lane & $13.92 \times 10^{-6}$ \\
\hline Urban & Multilane undivided & $12.47 \times 10^{-6}$ \\
\hline Urban & Multilane divided & $9.70 \times 10^{-6}$ \\
\hline Urban & One-way street & $2.18 \times 10^{-6}$ \\
\hline Urban & Freeway & \\
\hline
\end{tabular}

Source: Harwood and Russell 1990

Table 3-2. Truck accident rates by highway type

\begin{tabular}{|c|c|}
\hline Highway Type & $\begin{array}{c}\text { Truck Accident Rate } \\
\text { (accidents per mile) }\end{array}$ \\
\hline Controlled access & $3.8 \times 10^{-6}$ \\
\hline Noncontrolled access & $28.4 \times 10^{-6}$ \\
\hline Local streets & $15.6 \times 10^{-6}$ \\
\hline
\end{tabular}

Compiled from: Jovanis et al. 1989. 


\subsubsection{Accident Force Types and Force Magnitudes}

Two of the three parameters needed to determine the conditional probability of container failure are described in this section: (1) the conditional probability that, given an accident, a particular force type, e.g., impact, will occur and (2) the conditional probability that the force magnitude will exceed a certain value. The two parameters are presented together in this section because the source of data for both parameters is the same, the bases for any assumptions for each parameter type are frequently the same, and the results of the analysis are frequently intertwined for presentation and ease of use. The third factor, container failure threshold, is discussed in Sections 3.4.3 and 3.6.

The accident force type probability is derived directly from accident data; hence, comparing the original 1970 s data with current data is relatively easy. The accident force magnitude is determined by combining data, e.g., accident speeds, with analytical models, e.g., spring-mass description of truck tractor, trailer, and cargo striking a hard surface, that are not always adequately explained in the data source to permit independent computation. Thus, in some cases it is possible to verify initial data and/or assumptions but impossible to recompute final results on the basis of new data or assumptions.

The original analyses were for a truck trailer with a load of small radioactive material containers (Clarke et al. 1976), but the analyses should be applicable to typical hazardous material containers, e.g., 55-gal drums. A subsequent analysis was based on large, radioactive material containers but is applicable to the even larger bulk containers typical of hazardous materials (Dennis et al. 1978). Unless otherwise specified, the bulk transport data and analyses are from Dennis et al. (1978), and the small container data and analyses are from Clarke et al. (1976). In both cases, the researchers were from the Sandia National Laboratories (SNL) and were funded by DOT and DOE. In this report Clarke et al. (1976) and Dennis et al. (1978) are sometimes referred to generically as SNL because much of the basic data are the same and some of the analytical models are the same.

Five accident environments were defined and investigated: fire, impact, crush, puncture, and immersion. The fire temperature from hydrocarbon fuels varies from $1400^{\circ}$ to $2400^{\circ} \mathrm{F}$; an $1850^{\circ} \mathrm{F}$ fire temperature was considered as representative. Impact is defined as striking or being struck by an object that has no sharp projections. Crush is characterized by structural loads, either highly localized or over a large area, that cannot be described as impact or puncture. 
Puncture is defined as striking or being struck by an object that has the potential to penetrate the container. Immersion is not considered a threat to most containers; therefore, it is not presented further. (Criticality aspects are considered in separate administrative controls.) Detailed presentation of the data base is not appropriate for this Plan. The fire data are briefly summarized in the next few paragraphs to illustrate the nature and use of the data.

In 1986, researchers at LLNL (Fischer et al. 1987) concurred with the complete SNL fire model after an independent review of the data then currently available. Fires occur in approximately $1.6 \%$ of all truck accidents. (This value changes if roads are blocked; see Appendix A.) The fire duration distribution given in Fig. 3-3 is based on a statistical analysis process that incorporates a number of assumed probability distributions. Typical assumed distributions are given here for illustration.

1. In truck/truck collision there is a $2 \%$ chance that one or more of the trucks is a tanker carrying flammable goods.

2. A truck/tanker collision has available fuel that can vary in quantity from 0 to 10,000 gallons; the expected value is 5,000 gallons. The fuel cumulative distribution function (cdf) is given by

$$
1-e^{-(\operatorname{suc} 4571 \%)^{27}}
$$

3. No or minimal fire-fighting capability is available for $60 \%$ of accidents, a local fire department is summoned for $30 \%$ of accidents, and hand extinguishers are the only means used $10 \%$ of the time.

4. Local fire departments are effective against all fires. Unless a fire burns out before they arrive, the fire department limits the fire duration to between 15 and 45 minutes, with a uniform distribution.

If the risk analysis is for a tank truck containing flammable material, then assumptions 1 and 2 are neither appropriate nor conservative. If roads are closed, then assumptions 1 and 2 are very conservative. Assumption 3 is grossly conservative for LANL applications, and assumption 4 is very conservative.

To use Fig. 3-3, a container failure value is needed. For illustration, pick a failure threshold value of $20 \mathrm{~min}$. The probability that a truck fire burns $20 \mathrm{~min}$ or less is determined to be about 0.85 from Fig. 3-3. For risk analysis purposes, the value of interest is fires that burn 20 min or more, i.e., the conditional probability of a truck fire producing container failure, given a truck fire accident, is 0.15 for this example. 


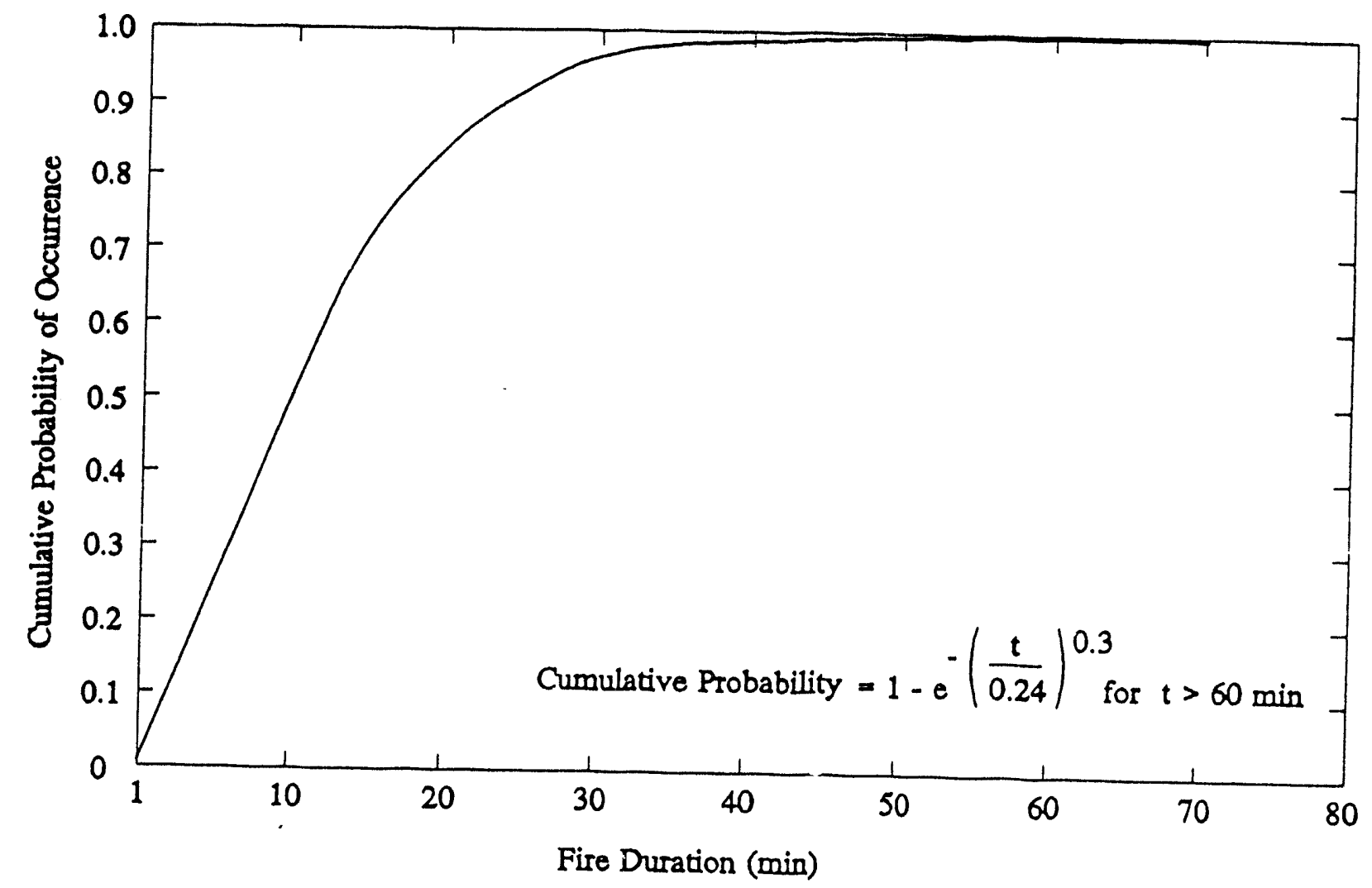

Source: Dennis et al. 1978

Fig. 3-3. Cumulative probability distribution of fire accident duration for truck transport of large containers 


\subsubsection{Conditional Container Failure Probability}

The historical methodology (described in Section 3.2) relies on data described in this section. The data in Sections 3.4.2 and 3.4.3 are not used together.

Any unintentional release of hazardous materials (except paint and paint-related material in packaging of 5 gal or less and batteries) during transportation, during loading or unloading, or in temporary storage related to transportation must be reported in writing to the DOT Research and Special Programs Administration (RSPA). Releases from any mode, excluding only bulk water transporters and motor carriers doing solely intrastate business, are included in a data base called the Hazardous Material Information System (HMIS). The data base is cataloged by 334 container types and 32 hazard class codes. The chemical name, amount released, whether a fire and/or explosion occurred, vehicle speed, number of highway lanes, whether the highway was divided or undivided, and other information are available for each entry. Despite potential underreporting, the Office of Technology Assessment (OTA 1986) found the HMIS to be the best source available for container failure data. Given a release, the HMIS contains a great deal of useful information about accidents and incidents, especially release amounts and container type. The HMIS cannot be used directly for the conditional probability of failure, given an accident, which is the primary focus of this section. The only readily available, systematic study of the HMIS that the author is aware of is for release amount by container type (Section 3.4.4).

The Federal Highway Administration (FHWA) Office of Motor Carriers maintains a data base of truck accident reports. An analysis of the data base (Harwood and Russell 1990) is presented in Table 3-3. The average probability of a release, given an accident involving hazardous materials, was $14.0 \%$ for the years 1984 and 1985 . The average for the years 1981 through 1985 was $15.2 \%$; the rate seems fairly constant. Harwood and Russcll (1990) acknowledge that the data base may be biased owing to underreporting. Since accident reporting levels increase as accident severity increases, $15 \%$ release, given an accident, is considered by Harwood and Russell (1990) to be an upper bound. The data in Table 3-3 show that liquid tankers are slightly more likely than average to experience a cargo release, but hazardous materials in general freight, explosives, and bulk gases are less likely than average to experience a release. To the extent that the cargo type descriptions in Table 3-3 are representative of specific commodities, e.g., gases in bulk for LPG, then the data can be used directly as the desired conditional release probability. The data for radioactive materials are very sparse. 
Table 3-3. Distribution of FHWA-reported truck accidents by cargo type, 1984 through 1985

\begin{tabular}{|c|c|c|c|c|c|c|c|c|c|}
\hline \multirow[b]{3}{*}{ Cargo Type } & \multirow{2}{*}{\multicolumn{2}{|c|}{$\begin{array}{l}\text { Accidents Involving } \\
\text { Trucks Not Carrying Hazmat }\end{array}$}} & \multicolumn{7}{|c|}{ Accidents Involving Trucks Carrying Hazmat } \\
\hline & & & \multicolumn{2}{|c|}{ Combined } & \multicolumn{2}{|c|}{ No Release } & \multicolumn{2}{|c|}{ Hazmat Release } & \multirow{2}{*}{$\begin{array}{c}\text { Release } \\
\text { Probability (\%) }\end{array}$} \\
\hline & No. & $\%$ & No. & $\%$ & No. & $\%$ & No. & $\%$ & \\
\hline General freight & 23,651 & (33.7) & 741 & (20.1) & 680 & (21.4) & 61 & (11.8) & 8.2 \\
\hline Gases in bulk & 42 & $(0.1)$ & 259 & $(7.0)$ & 238 & $(7.5)$ & 21 & (4.1) & 8.1 \\
\hline Solids in bulk & 1,310 & (1.9) & 40 & $(1.1)$ & 28 & $(0.9)$ & 12 & (2.3) & 30.0 \\
\hline Liquids in bulk & 1,618 & $(2.3)$ & 1,831 & $(49.6)$ & 1,486 & $(46.8)$ & 345 & $(66.6)$ & 18.8 \\
\hline Explosives & 12 & $(0.1)$ & 70 & (1.9) & 63 & $(2.0)$ & 7 & (1.4) & 10.0 \\
\hline Empty & 15,989 & (22.8) & 220 & $(6.0)$ & 210 & (6.6) & 10 & (1.9) & 4.5 \\
\hline Other & 27,478 & (39.2) & 529 & (14.3) & 467 & $(14.7)$ & 62 & $(12.0)$ & 11.7 \\
\hline TOTAL & 70,100 & & 3,690 & & 3,172 & & 518 & & 14.0 \\
\hline
\end{tabular}

Source: Harwood and Russell 1990. 
The conclusion to be drawn from this subsection is that the historical approach is not feasible for radioactive material containers or for most hazardous materials containers.

\subsubsection{Release Amount}

Abkowitz et al. (1984) used the HMIS to estimate fractional release amount by container type for a variety of hazardous materials. A 0.20 conditional probability of release, given an accident, is incorporated into the results, which are expressed in fraction leaked per mile. For the risk analysis approaches discussed in this report, the desired parameter is the amount leaked, given a leak occurs. Thus, these data are not useful for the LANL Workbook.

A cumulative probability distribution is the most desirable data form, and some of these distributions are being developed for bulk liquids by researchers at the University of Waterloo. A general release amount distribution for bulk liquid hazmat is recommended by FEMA et al. (undated), but bulk liquid is not applicable to the LANL Workbook.

Release amounts for radioactive materials, primarily solids, have been used in a number of DOE and NRC reports including some prepared by the author. The RADTRAN 4 technical manual is planned for release in the Fall of 1993. It is hoped that this manual will contain the most recent values. If not, a data search will be instituted for the Workbook.

\subsection{ACCIDENT SCENARIO DEVELOPMENT}

\subsubsection{Fault Trees}

Accident scenarios are usually developed using fault trees and event trees. A fault tree is a graphic presentation of the systematic, logical development of the many causes of an undesirable event. Fault trees have been used extensively in transportation risk analysis. Fault tree analysis begins with an undesirable event called the top event, for example, "release from transport accidents". The next step is to identify the immediate, necessary, and sufficient causes of the top event. Each of the immediate causes is examined in turn to determine its immediate causes. This process continues until the analyst has obtained the desired level of resolution of causes. Each cause will later be assigned probabilities or frequencies from the available data. 
Fault tree construction is described in more detail in Appendix B, where the tree in Fig. 3-4 is developed.

\subsubsection{Event Trees}

An event tree is a graphical model for identifying and evaluating potential outcomes from a specific initiating event. The event tree depicts the chronological sequence of events, i.e., accident scenarios, that could result from the initiating event.

The first step is to identify the initiating event, for example, "transport accident occurs." The analyst asks what protective system action, operator action, normal system function, and so forth is expected to occur next. Each event following the initial event is conditional on the preceding event. The outcomes of the events are usually binary, i.e., the success or failure of an operator action or alternatively, yes, the safety system functioned, or no, it did not.

Event tree construction is described in more detail in Appendix $C$, where the event tree in Fig. 3-5 is developed. For many LANL risk analysis applications the event tree shown in Fig. 3-5 is adequate. Notice how values for the probabilities can be inserted onto the tree for quantification.

\subsubsection{Screening}

Screening occurs on several levels. The first screening occurs after hazards are identified. For the purpose of this report, shipments in certified containers are screened out. That is, the focus of this report is on shipments in noncertified containers. (A certified container may be analyzed to establish a benchmark for later relative risk analysis of a noncertified container.)

Once scenarios are identified, another screening takes place based on either frequency or consequence. Trivial releases are screened out on consequence. Incredible accidents are screened on frequency. (The definition of incredible is generally defined as less frequent than $10^{-6} /$ year.) Accident releases from defective containers or human error to properly close the container can be shown to be negligible on the basis of frequency; a similar consequence occurs from an accident of much higher frequency. Human error that leads to a release without an accident, i.e., a nonaccident release, cannot generally be excluded on the basis of frequency. 


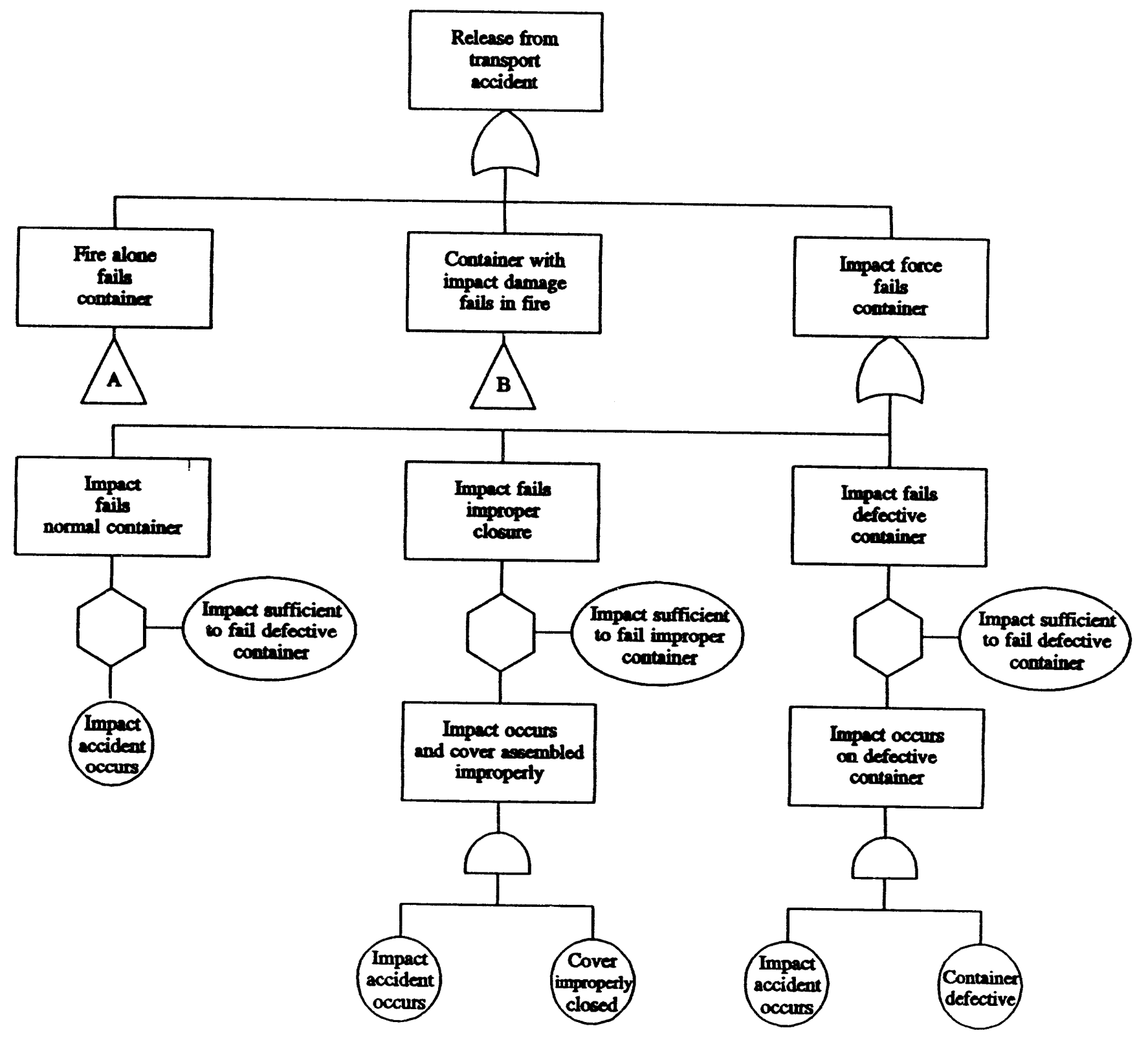

Fig. 3-4. Example fault tree 


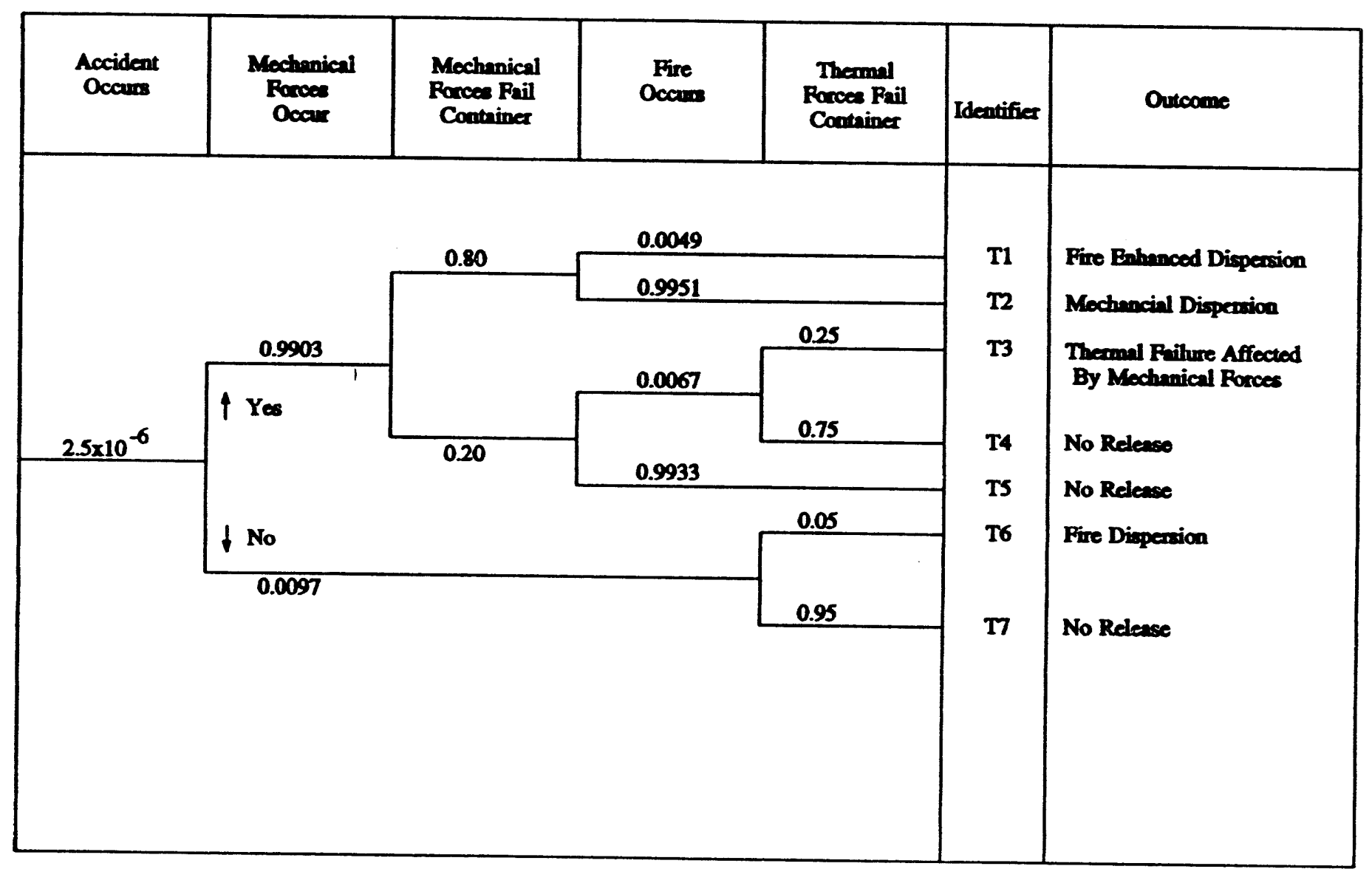

Fig. 3-5. Example event tree 


\subsection{CONTAINER FAIIURE THRESHOLD ESTIMATES}

Estimates of the container failure thresholds are potentially the most complex and expensive part of an absolute transportation quantitative risk analysis. These estimates are also the key feature of most anticipated LANL applications, e.g., the container is known not to meet certification requirements, which infers that an estimate exists of how close the container comes to meeting the requirements. The difference is key to the potential LANL relative risk analyses described in Section 4. An elaborate or expensive calculation is not required for many LANL applications; a best estimate with upper and lower bounds may be all that is required.

The primary alternatives for determining failure thresholds are (1) values from the literature including the regulations, (2) engineering judgement, (3) similarity analyses, (4) tests, and (5) direct calculation. Risk analyses in the literature may contain failure thresholds suitable for other risk analyses; an example is an $U_{6}$ cylinder (Geffen et al. 1798). This is clearly the easiest way to obtain needed values. Another possibility is to use the regulatory values, e.g., a 30-ft drop, for certified containers. This will be conservative since failure does not occur for only a slightly higher drop height.

Engineering judgement can be used to extrapolate from prior analyses and/or from the limited accident/test data available. This alternative may be the only practical one when resources are limited.

The concept of physical similarity is that two systems will behave similarly if ratios of physical quantities such as forces and velocities are the same. This concept led to the development of dimensionless parameters for heat transfer and fluid flow, e.g., the Reynolds and Nusselt numbers; this concept is also the basis for studying phenomena by using scale models (Grober et al. 1961).

Tests are usually performed to show that a container meets regulatory criteria without failure. Therefore, existing test data would usually indicate that the failure forces are greater than those experienced in the test, but how much greater may be difficult to estimate. The testing approach for failure thresholds is (1) estimate a force magnitude, e.g., drop height from impact testing, that would cause failure; (2) perform the test; and (3) raise or lower the test force to bracket the failure threshold. Clearly, depending on the estimating ability of the test director and the accuracy desired for the failure threshold, 5,10 , or more tests may be required. If containers are inexpensive, testing may be a practical approach. 
Direct calculations fall into two categories: hand calculations and computer calculations. Hand calculations are generally limited to simple geometries; linear, elastic structural analyses; and steady-state, one-dimensional heat transfer calculations. Computer analyses can be much more

sophisticated. A complex heat transfer analysis can be relatively inexpensive compared with a complex structural analysis. For a complex container design, a complex structural analysis is potentially limited only by the financial resources of the project.

The approaches previously described have been presented in approximate order of increasing demand on project resources. The accuracy does not necessarily correspond to cost; for example, a good analysis from the literature is probably the least expensive and can also be the most accurate. Testing has the advantage of using the real thing, whereas analytical models are, by necessity, mathematical approximations to the real world. On the other hand, with a reasonable analytic model, parameter studies can be easily performed either to determine failure thresholds or to determine the effect of proposed mitigation strategies. As is the case for most aspects of risk analysis, the analyst must choose the approach that best suits the project objectives and resources. No one method is best for all or even most situations.

The objective of an engineering model is to show the relationship between the design features of interest and the accident forces of interest. If the scope of the risk analysis relates to the performance of only a portion of the design, e.g., the ability of the valves and valve enclosure to resist accident forces, then the appropriate engineering model would cover these aspects in detail and the remainder of the container in as little detail as possible.

\subsection{CONSEQUENCE ANALYSIS}

The materials of interest for LANL risk management applications are expected to be friable solids, powders, nonfriable solids, liquids and gases under pressure, explosives, and nonpressurized liquids. The primary mechanism for exposing people to these hazardous materials is atmospheric dispersion of materials made airborne by accident forces. Explosives are a special case; effects are directly proportional to the amount of explosives and inversely proportional to the distance from the explosion. Nonpressurized liquids may form pools that must evaporate to expose people to potential inhalation hazards. Direct radiation exposure from nondispersed material is a consideration. 
Models for explosives and for Gaussian dispersion of aerosols and gases will be incorporated into the Workbook. Most analyses of interest can be performed by using these models.

Population-at-risk isopleths will be constructed on the basis of data from ENG-2 for onsite persons. The data source(s) for offsite population are census data and others to be identified.

\subsection{RISK PRESENTATION AND ASSESSMENT}

The two types of risk measures are individual risk and societal risk. Individual risk reflects the frequency of a specific health effect at a specific geographical location. Individual risk calculations are used to answer the question: How does the risk to an individual vary with location? Societal risk reflects the frequency of health effects (usually fatalities) in a specific population occurring as the result of exposure to a specified hazardous material.

\subsubsection{Risk Acceptability}

DOE has adopted two quantitative safety goals to limit the risks of fatalities associated with its nuclear operations (USDOE 1991). These goals are the same as those established for nuclear powerplants by NRC.

\section{Goal for Individual Risk to the Public}

The risk to an average individual in the vicinity of a DOE nuclear facility for prompt fatalities that might result from accidents should not exceed one-tenth of one percent $(0.1 \%)$ of the sum of prompt fatalities resulting from other accidents to which members of the population are generally exposed. For evaluation purposes, individuals are assumed to be located within 1 mile of the site boundary.

\section{Goal for Societal Risk to the Public}

The risk to the population in the area of a DOE nuclear facility for cancer fatalities that might result from operations should not exceed one-tenth of one percent $(0.1 \%)$ of the 
sum of all cancer fatality risks resulting from all other causes. For evaluation purposes, individuals are assumed to be located within 10 miles of the site boundary.

The extent to which the DOE has implemented this policy is unclear and will require further development for the Workbook. Some specific interpretations do exist but are apparently not widely accepted. Proposed risk acceptance criteria for exposure to radionuclides for the public and an onsite worker, respectively (USDOE 1993) are shown in Figs. 3-6 and 3-7. The criteria currently used at the Hanford Site for onsite transportation (Field 1993) are shown in Figs. 3-8 and 3-9.

Clearly, acceptable transportation risk criteria can be developed and used by LANL as a risk management tool. The criteria need not be universally accepted, only defensible.

\subsubsection{Standard Risk Presentation Methods}

Two presentation techniques are generally used for individual risk: risk contours that are isopleths of constant individual risk shown in a map format and risk profiles that show individual risk as a function of distance. In both cases, the expected frequency of the specified health effect is shown regardless of whether or not anyone is present at the location. A risk profile is shown in Fig. 3-10. Note that the geographic dependency stated in the individual public risk goal is "within 1 mile of the DOE boundary."

The most common societal risk presentation technique is an F-N curve, which is a graph of the number of fatalities $(N)$ on the abscissa and frequency $(F)$ of $N$ or more fatalities on the ordinate. An example F-N curve is shown in Fig. 3-11. Note that frequency appears on the abscissa in Figs. 3-7 through 3-9 and on the ordinate in Fig. 3-11. In addition, the frequency in the former figures is not curnulative; these are called $f-n$ curves. The $f-n$ version of Fig. 3-11 is shown in a histogram format in Fig. 3-12. Despite the potential conceptual problem due to the cumulative frequency, the F-N curve has become the norm for quantitative risk analyses and the comparison of risk alternatives for both stationary plants and transportation routes. It appears likely, however, that DOE will focus on the f-n format. 


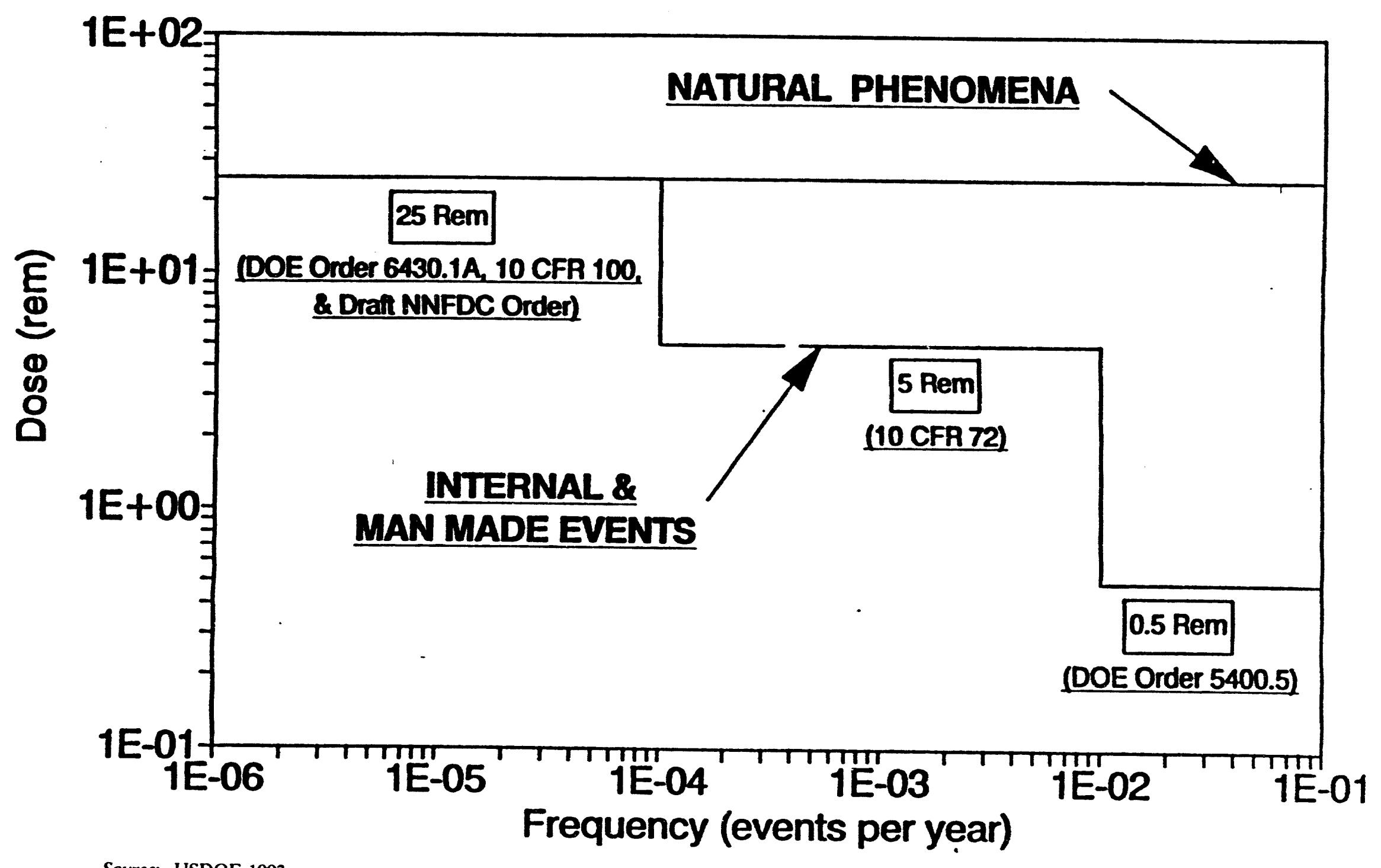

Source: USDOE 1993

Fig. 3-6. Public radiological criteria 


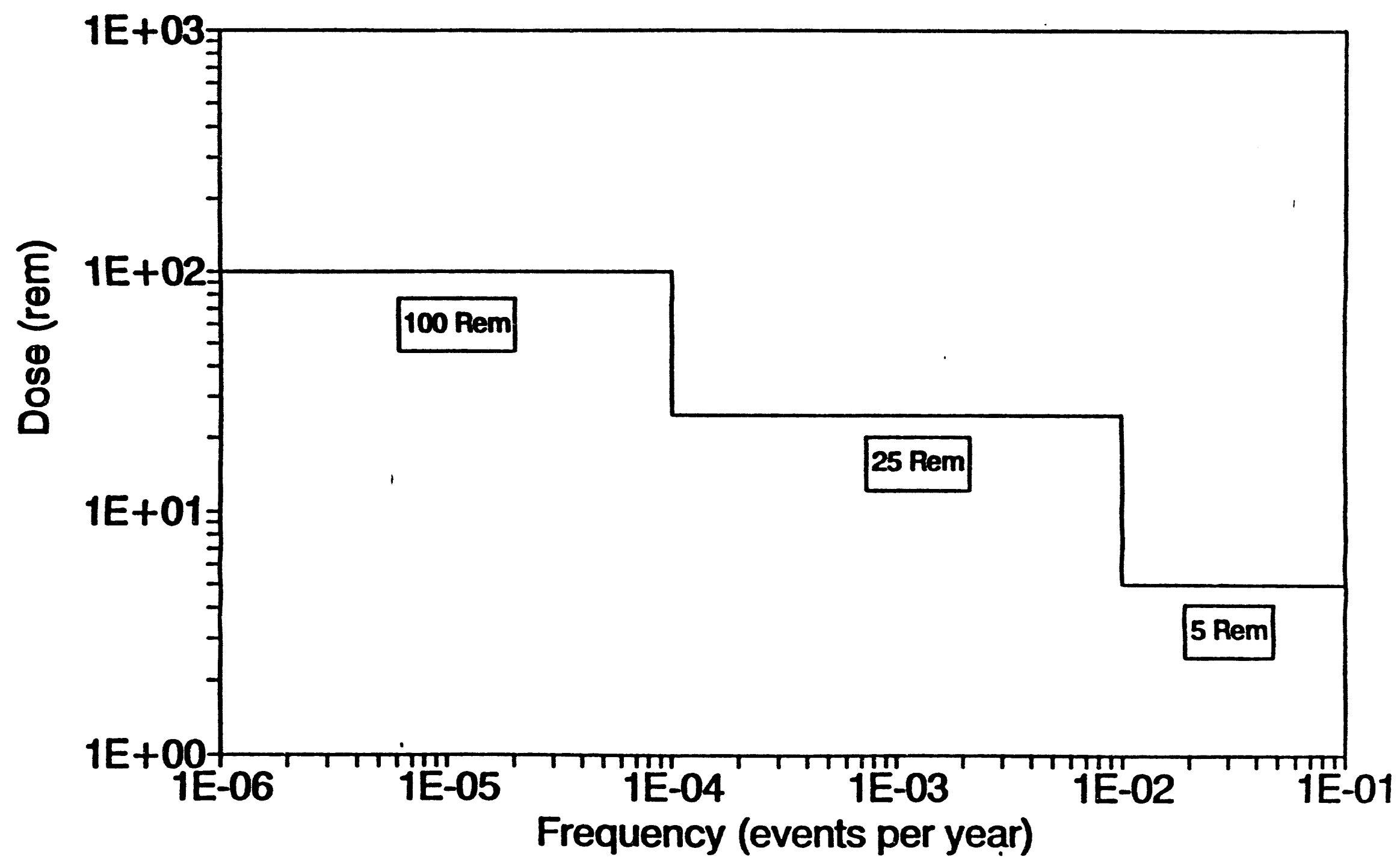

Source: USDOE 1993

Fig. 3-7. Co-located worker radiological criteria 


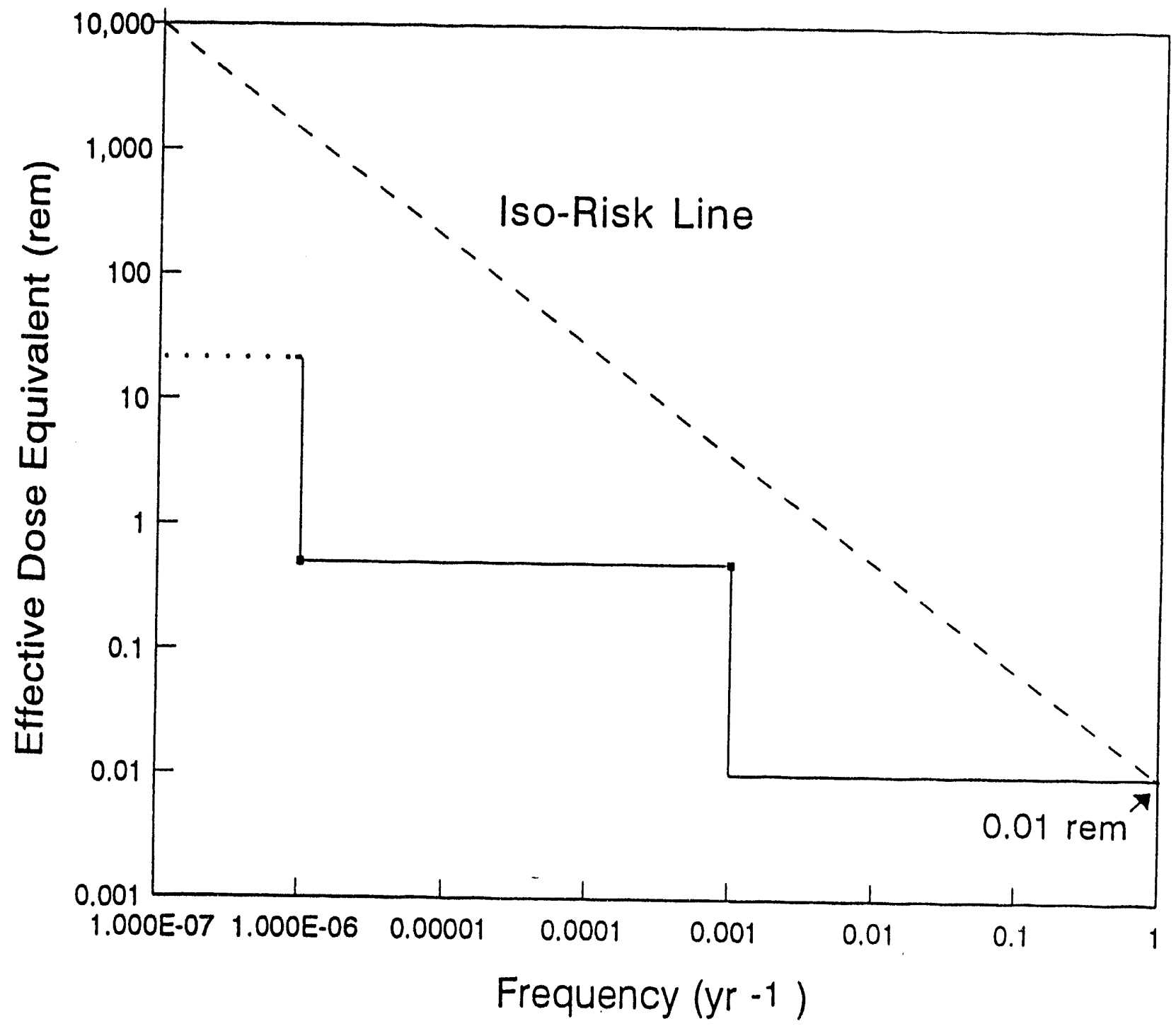

Source: Field 1993

Fig. 3-8. Hanford radiological risk acceptance guidelines (offsite public) 


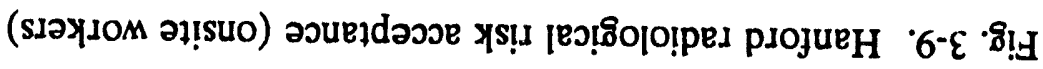

E66I PIग!] :22mos

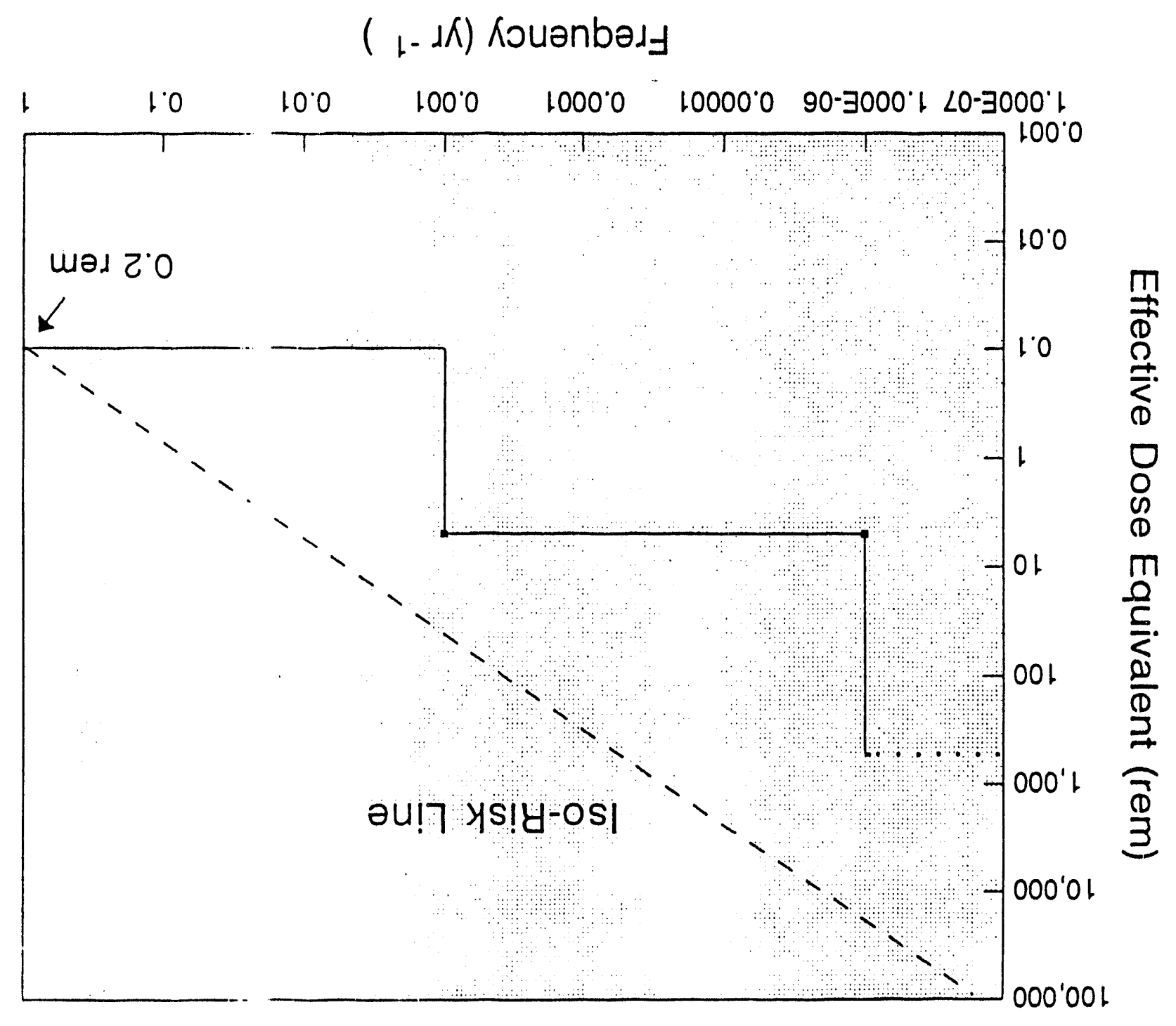




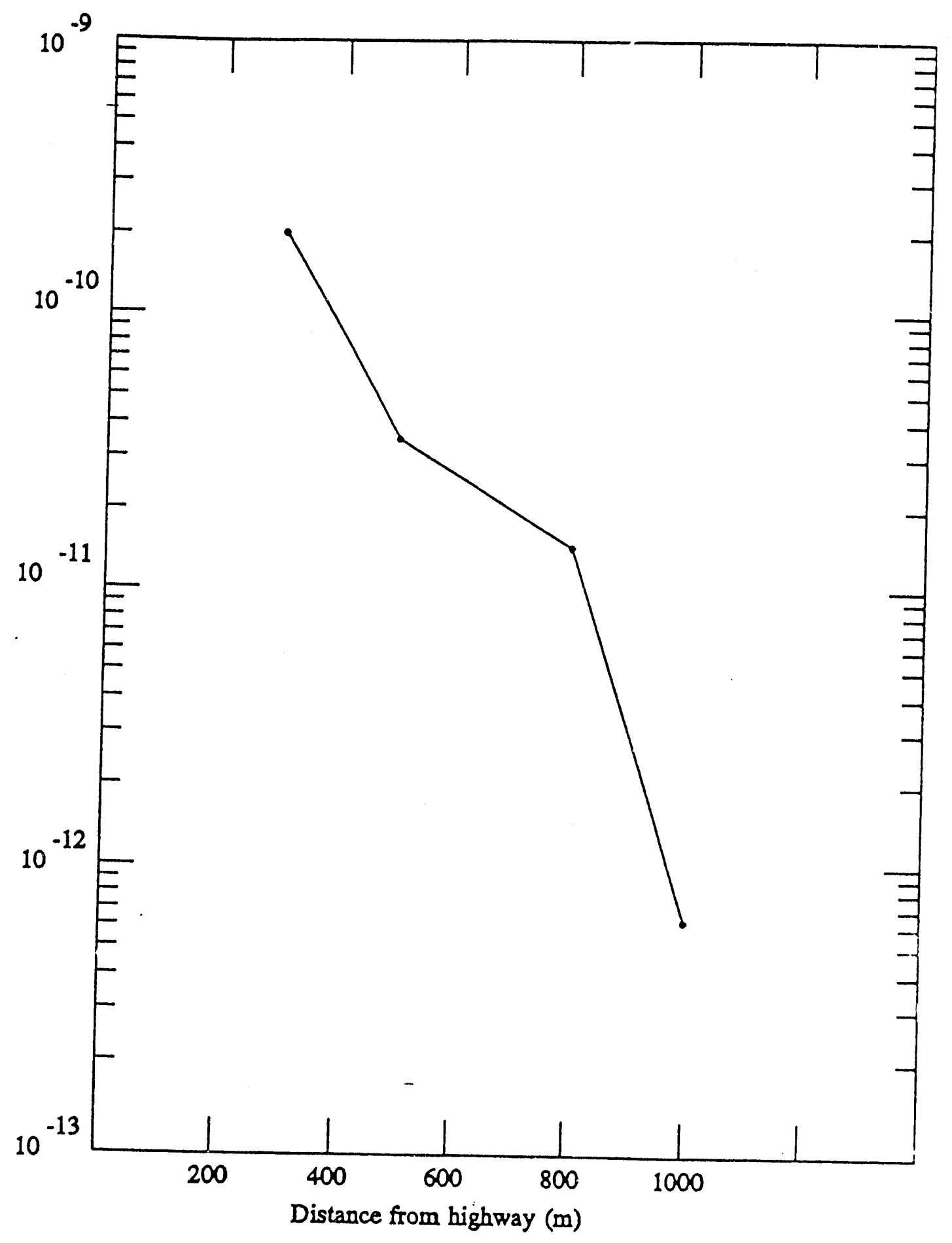

Soutce: Rhyne In Press

Fig. 3-10. Example of individual risk profile 


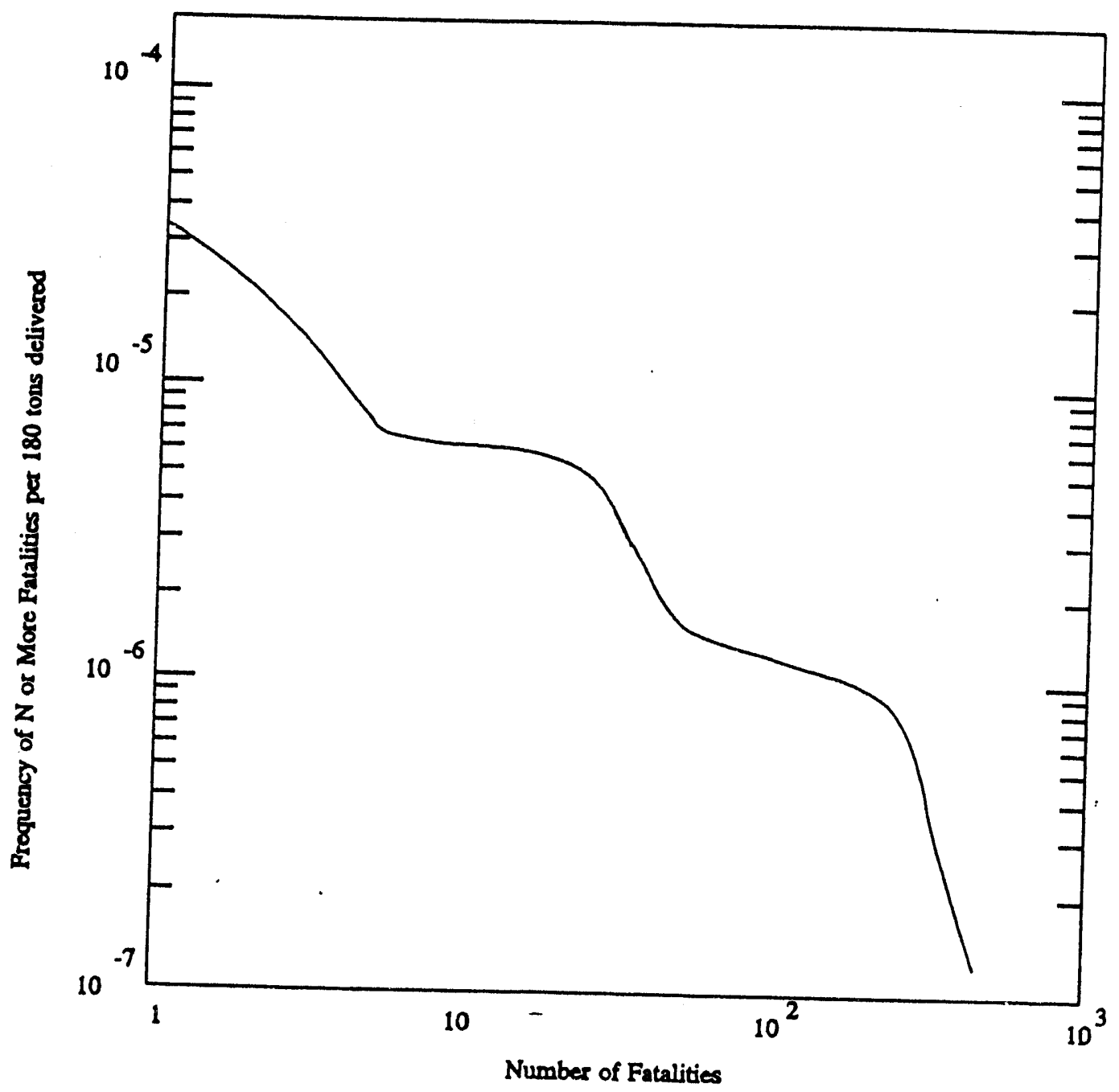

Source: Rhyne In Press

Fig. 3-11. Example of societal risk F-N curve 


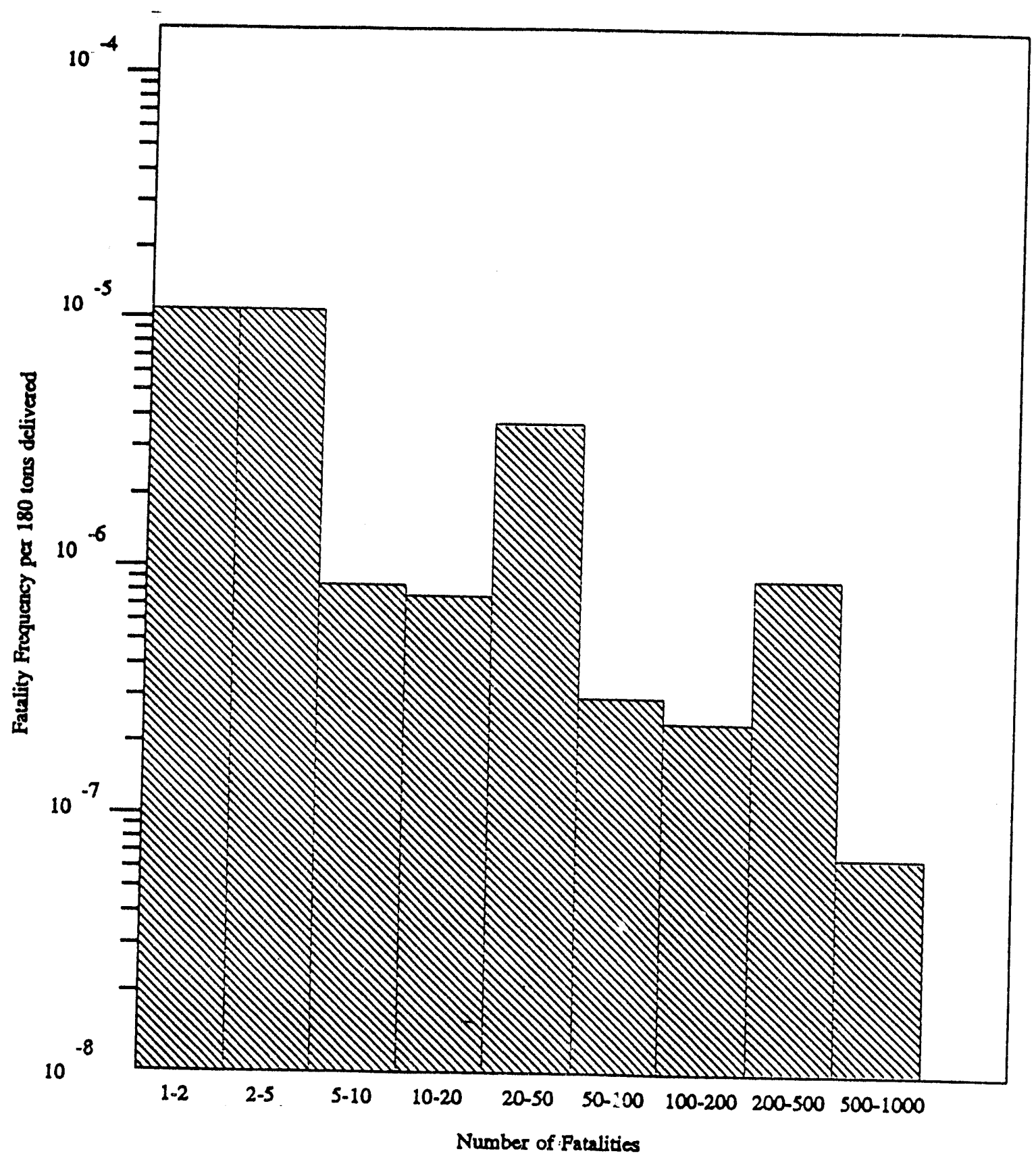

Source: Rhyne In Press

Fig. 3-12. Example of societal risk profile histogram 
Both societal risk and individual risk can be computed and presented for each route segment to enhance understanding of risk variation along the route. This extra effort should not be needed for LANL applications. Societal risk is proportional to the route length, but individual risk is not. Because of its geographical nature, individual risk is probably of more interest to persons who work or live along a particular route segment than societal risk. However, individual risk profiles or contours generally reflect numerical values that are so small that they may not be meaningful to the public.

\subsubsection{Uncertainty}

The uncertainty in an absolute risk analysis is one or more orders of magnitude and can mask risk comparison efforts. The uncertainty in a relative risk analysis is less, but can still be greater than the difference between two alternatives.

One way to incorporate uncertainty into the acceptable/unacceptable decision is shown in Fig. 3-13 (Rougemont and Bolig 1991). The matrix $f-n$ risk presentation format shows acceptable and unacceptable zones and two additional zones: (1) acceptable but management review required before proceeding and (2) undesirable requiring management decision to investigate risk reduction potential before proceeding. A three zone approach is used in the United Kingdom: a tolerable zone, an intolerable zone, and a zone in which additional risk reduction measures are to be incorporated as reasonably practicable.

The recommended approach for LANL is acceptable risk guidelines such as those in Figs. 3-8 and 3-9 with the addition of two bands corresponding to (1) management review required before proceeding and (2) management decision regarding uncertainty and potential risk reduction required before proceeding. This will result in the four zones of Fig. 3-13 in a $\mathrm{f}-\mathrm{n}$ curve format. 


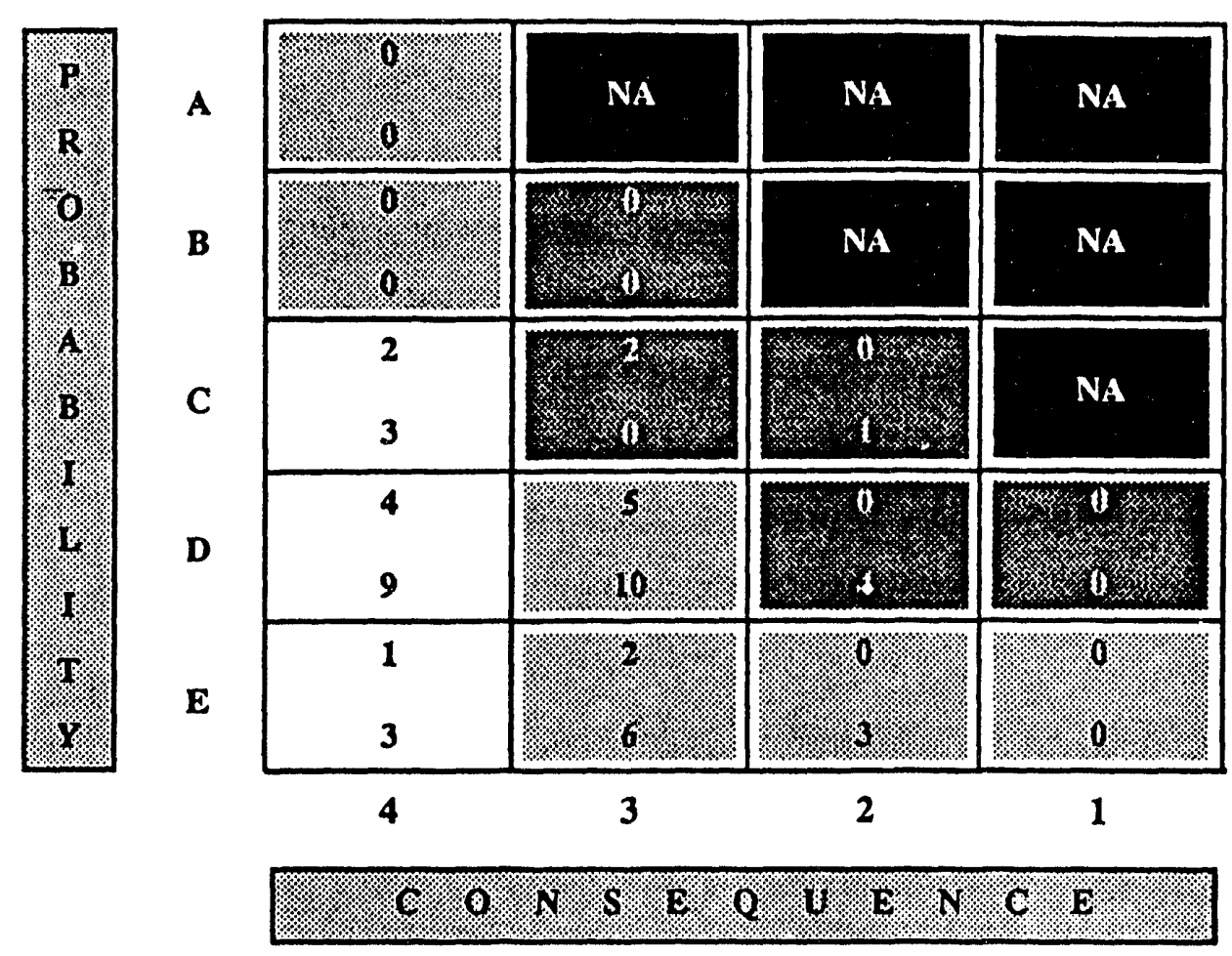

\section{LEGEND -}

- Consequence is equivalent to hazard severity. (One is more severe than four.)

- $\mathrm{NA}=$ Not Acceptable.

- Each square represents one applicable risk assignment level.

- The number in the upper half of each applicable risk assignment level represents the TA-6 Scenario total.

- The number in the lower half of each applicable risk assignment level represents the CGPF Scenario total.

- The acceptance risk envelope is all the region below and to the left of N/A areas, providing they meet the decision criteria explained below.

\section{Category Hazard RiskIndex Decision Criterio}

Category 1 .................... $1 B, 1 C, 2 A, 2 B, 3 A \ldots \ldots . . . . . . .$. Unacceptable - Action must be taken to reduce risk.

Category 2..................ID, 2C, 2D, 3B, $3 C$ Unacceptable - Action must be taken to reduce risk
Undesirable - Managing activity decision required.

Category 3 $1 E, 2 E, 3 D, 3 E, 4 A, 4 B$ Acceptable - Requires review by managing activity.'

Category 4 $4 C, 4 D, 4 E$ Acceptable - No review is required.

Source: Rougemont and Bolig 1991

Fig. 3-13. Risk presentation incorporating management review requirements 


\section{CONCLUSIONS AND RECOMMENDATIONS}

\subsection{CONCLUSIONS}

(1) The PTM being developed by LANL will be the governing document for onsite, offsite, and intralaboratory shipments. The PTM will be supported by safety documentation, procedures, QA documentation, and so forth.

(2) QRA has a role in the PTM as a risk management tool. Both relative and absolute QRA can be used to make good decisions at LANL. The primary use for QRA is expected to be for onsite shipments in noncertified containers.

(3) MAT-2 needs a risk management tool. The lool should not require substantial support from specialized safety and risk analysis personnel, e.g., HS-3, for many applications. The tool should have the potential to be automated on a personal computer (PC).

\subsection{RECOMMENDATIONS}

(1) A risk management tool should be developed in a worksheet format (the Workbook). Default values should be given to help the user determine appropriate parameters and to provide a self-checking mechanism. A typical worksheet would look like Fig. 4-1.

(2) Phase 1 of the development of the Workbook should be the simultaneous creation of the worksheets and the performance of an absolute QRA for an example container to provide default values for the Workbook. The example should be chosen so that future users can easily relate to the default values. The example should not require the performance of expensive failure threshold calculations. In fact, the use of best estimates with upper and lower bounds would be an illustration that not all applications require expensive supporting analyses. 


\begin{tabular}{||l|c|c|}
\hline \multicolumn{1}{|c|}{ Calculate the value of ND2 for rural interstates } & $\begin{array}{c}\text { Input } \\
\text { Value }\end{array}$ & $\begin{array}{c}\text { Default } \\
\text { Value }\end{array}$ \\
\hline 1. Enter miles per trip on rural interstate & & 277 \\
\hline 2. Enter number of vehicles per hour on rural interstate & & 2800 \\
\hline 3. Enter average vehicle speed on rural interstate $(\mathrm{mph})$. & & 55 \\
\hline 4. Enter average number of persons per vehicle & & 2 \\
\hline 5. Divide $3600+(3)$ & & 65 \\
\hline 6. Add $161+(5)$ & & 226 \\
\hline 7. Multiply (6) $\times(1)$ & & $6.26 \times 10^{4}$ \\
\hline 8. Multiply $(7) \times(2)$ & & $1.75 \times 10^{8}$ \\
\hline 9. Divide $(8)+(3)$ & & $3.13 \times 10^{6}$ \\
\hline 10. Divide $(9)+(3)$ & & $5.78 \times 10^{4}$ \\
\hline 11. Multiply $(10) \times(4)$ & & $1.16 \times 10^{5}$ \\
\hline
\end{tabular}

Fig. 4-1. A typical worksheet 
(3) Subsequent phases of the Workbook development should be to provide examples of different types of analyses and to assure that the Workbook is flexible enough to handle the different types of analyses. (It is unlikely that complete flexibility will be incorporated in the initial version of the Workbook.) The types of analyses that should be developed include, but are not limited, to those listed here. Note that one example may illustrate more than one analysis feature.

a. Use a relative risk analysis to select the best (minimum risk) onsite route; consider only accident rate, route length, and exposed population. Use Eq. (3-5) to make the selection.

b. Show that the normal administrative control of road closure reduces accident frequencies to a level equivalent to Type $B$ certification requirements. The equivalency argument is based on showing that $F_{1}{ }^{x} P_{2}{ }^{x} P_{3}{ }^{x}$ evaluated for road closure and the noncertified container is less than $F_{1}{ }^{y} P_{2}{ }^{y} P_{3}^{y}$ for the certified container. See Eq. (3-4). (This argument is based on release probability alone; therefore, it may not be sufficient to show shipments are safe.)

c. Perform an absolute risk analysis to show that the use of a noncertified container is safe. Equation (3-2) is evaluated for an absolute risk analysis. (If not analyzed in Phase 1, the pressure cooker is a candidate for this analysis.)

d. Perform absolute risk analyses to serve as benchmarks for future relative risk analyses to show that proposed shipments are acceptable. Evaluate Eq. (3-2) initially as the benchmark. A subsequent relative risk analysis uses fewer terms as appropriate. (Candidates are weapons components and irradiated target containers.) 
e. Use the results of item $\mathrm{c}$ to show how a variety of container modifications is analyzed to produce quantitative risk reduction estimates. One example should show how the container design parameters are determined to meet a predetermined numerical risk goal.

(4) Automate the Workbook on a PC. 


\section{REFERENCES}

Abkowitz, M., A. Eiger, and S. Srinivasan. 1984. Assessing the Releases and Costs Associated with Truck Transport of Hazardous Wastes. PB84-224468. U.S. Environmental Protection Agency.

Arendt, J. S., D. D. Lorenzo, and A. F. Lusby. 1989. Evaluating Process Safety in the Chemical Industry - A Manager's Guide to Quantitative Risk Assessment. Washington, D.C.: Chemical Manufacturers Association.

Clarke, R. K., et al. July 1976. Severities of Transportation Accidents. SLA-74-0001. Sandia National Laboratories.

Dennis, A. W., et al. May 1978. Severities of Transportation Accidents Involving Large Packages. Report SAND77-0001. Sandia National Laboratories.

FEMA (Federal Emergency Management Agency), U.S. Department of Transportation and U.S. Environmental Protection Agency. Undated. Handbook of Chemical Hazard Analysis Procedures.

Fischer, L. E., et al. 1987. Shipping Container Response to Severe Highway and Railway Accident Conditions. NUREG/CR-4829. Lawrence Livermore National Laboratory.

Geffen, C. A. et al. 1978. An Assessment of the Risk of Transporting Uranium Hexafluoride by Truck and Train, PNL-2588, U.S. Department of Energy, Pacific Northwest Laboratory.

Grober, H.. S. Erk, and U. Griyull. 1961. Fundamentals of Heat Transfer. New York: McGraw-Hill Bonk Co., Inc.

Harwood, D. W., and E. R. Russell. May 1990. Present Practices of Highway Transportation of Hazardous Materials. FHWA-RD-89-013. U. S. Department of Transportation. 
HSE (Health and Safety Executive). 1988. The Tolerability of Risk from Nuclear Power Stations. Her Majesty's Stationery Office, London, United Kingdom.

Jovanis, P. P., H. L. Chang, and I. Zabaneh. 1989. A comparison of accident rates for two truck configurations. Transportation Research Record 1249, pp. 18-29. Washington, D.C.: Transportation Research Board, National Research Council.

LANL (Los Alamos National Laboratory). June 30, 1993a. Packaging \& Transportation Manual, Consisting of 5 of 15 proposed chapters.

LANL (Los Alamos National Laboratory). May 20, 1993b. Quality Assurance Plan for Hazardous Materials Packaging and Transportation for the Los Alamos National Laboratory Packaging and Transportation Program.

Modern Bulk Transporter. June 1990. "Usher Transport Includes Customers, Others in Overall Safety Program." Modern Bulk Transporter, 52, 12, 36-43.

Neuhauser, K. S., and F. L. Kanipe. January 1992. RADTRAN 4: Volume 3, User Guide, SAND89-2370, U.S. Department of Energy, Sandia National Laboratories.

OTA (Office of Technology Assessment). 1986. Transportation of Hazardous Materials. Report OTA-SET-304. U.S. Congress, Office of Technology Assessment.

Rhyne, W. R. In Press. Quantitative Risk Analysis of Transporting Hazardous Materials by Truck and Train. New York: Van Nostrand Reinhold.

Rhyne, W. R., et al. "Probabilistic Source Term for Accidents Associated with the Transport of Chemical Munitions," presented at the AlChE Annual Meeting, August 21-24, 1988, Denver, Colorado.

Rougemont. G. and R. Bolig. August 1991. Safety Assessment for the Compressed Gas Processing Facility, Los Alamos National Laboratory. 
Rowe, W. D. November 1983. Risk Assessment Processes for Hazardous Materials Transportation. Transportation Research Board National Cooperative Highway Research Program Synthesis of Highway Practice Report 103. Washington, D.C.: Transportation Research Board, National Research Council.

Sandquist, G. M., et al. 1992. "Risk Assessment of Radioactive and Hazardous Materials in DOE Defence Package Transport Accidents," Int. J. Radioactive Materials Transport, 2, 3, 121 128.

USDOE (U.S. Department of Energy). Sept. 9, 1991. Nuclear Safety Policy, Secretary of Energy Notice SEN-35-91.

USDOE (U.S. Department of Energy). March 5, 1993. DOE Standard: Definitions and Criteria for Accident Analysis, DOE-DP-STD-3005-93 (Proposed). 
APPENDIX A

EFFECT OF ROAD CLOSURE

A - 1 


\section{APPENDIX A \\ EFFECT OF ROAD CLOSURE}

Closing the road during transportation of hazardous materials will affect the following: the accident rate; the probability that a particular force, e.g., fire, will occur, given an accident; the distribution of mechanical force magnitude, given an accident producing a mechanical force; and the distribution of fire magnitude, given an accident producing a fire.

\section{A.1 ACCIDENT RATE}

After a road is closed, MAT-2 personnel conduct a sweep to ensure that the route is free from natural and man-made safety hazards. The hazmat truck is escorted along the route at the posted speed limit. An emergency vehicle may require access to the route either because of a LANL emergency or because a person stopped at the roadblock declares an emergency. The hazmat truck is guided to the side of the road while emergency vehicle(s) or personal cars and their escort(s) pass. A roadblock violator may also be on the route.

A partial listing of the factors considered to affect truck accidents is shown in Table A-1 (Harwood and Russell 1990). Data are lacking to correlate accident rate with most of these factors. The types of truck accidents are shown in Table A-2 (Harwood and Russell 1990). These values correlate well (Rhyne In Press) with earlier studies that are used to determine accident force magnitude (Clarke et al. 1976) and truck collision and noncollision scenarios (Fisher et al. 1987). The estimated accident rate reduction effect of road closure is shown in the third column of Table 4-2. The approach is to reduce accidents by a factor of 10 if the escort vehicle(s) is the only or the major consideration, e.g., rear-end collisions; reduce accidents by a factor of 100 if emergency/violator vehicles are the only consideration, e.g., head-on collisions; reduce other factors affected by the closure to zero, e.g., truck/train collisions; and retain all factors not affected by the closure, e.g., vehicle fire. [This procedure has been used and defended by the author previously (Rhyne et al. 1988).] The net effect is to reduce the overall accident rate for typical highways by a factor of 12 . 
Table A-1. Partial listing of factors considered to affect truck accidents

Truck Type or Configuration

Number of trailers

Number of axles on tractor/trailer(s)

Cab type

Cargo area configuration

Truck Size and Weight

Width of trailer

Length, overall

Length, trailer(s)

Empty/loaded

Weight, gross

Weight, trailer

\section{Truck Operations}

\section{Cargo type}

Operator type

Trip type

\section{Truck Driver}

Age

Experience with rig

Hours of service

Driver condition

Location

State

Urban/rural

\section{Highway}

Function

Access control

Number of lanes

Lane width

Shoulder width

Shoulder surface

Median width

Horizontal alignment

Vertical alignment

Surface condition (wet/dry/etc.)

Pavement condition

Pavement type

\section{Traffic}

Volume (average daily traffic)

Volume (day/night)

Percent trucks

\section{Environment}

Visibility

Weather

Light

\section{Temporal}

Month/season of year

Day of week

Time of day 
Table A-2. Truck Accident Type Distribution

\begin{tabular}{||c|c|c|}
\hline \multirow{2}{*}{ Tractor-Trailer } & \multicolumn{2}{|c|}{ Fractional Distribution } \\
\cline { 2 - 3 } Accident Type & Normal $^{(\mathbf{s})}$ & Road Closed \\
\hline \hline Noncollision & & 0.0062 \\
Ran off road & 0.062 & 0.0077 \\
Jackknife & 0.077 & 0.0072 \\
Overturn & 0.072 & 0.004 \\
Separation of units & 0.004 & 0.006 \\
Fire & 0.006 & 0.009 \\
Other & 0.009 & \\
Collision & & 0.0114 \\
Fixed object & 0.114 & 0.0093 \\
Parked vehicle & 0.093 & 0.0 \\
Train & 0.005 & 0.0015 \\
Nonmotorist & 0.015 & 0.0034 \\
(e.g., pedestrian) & & \\
Other & 0.034 & 0.00015 \\
Head-on collision & & 0.0133 \\
Rear-end collision & 0.015 & 0.00185 \\
Sideswipe & 0.133 & 0.00103 \\
Angle & 0.185 & 0.00070 \\
Other & 0.103 & 0.0827 \\
\hline TOTAL & 0.070 & \\
\hline
\end{tabular}

(a) Source: Harwood and Russell 1990

$$
\text { A }-4
$$


It is interesting to note in that the difference between controlled access and noncontrolled access highways in Table 3-2 is a factor of 7.5. Since road closure eliminates even more accidents, the factor of 12 given above appears consistent. Clearly, the reduction factor of 12 would not apply to controlled access highways.

The effect of other parameters in Table A-1 will be investigated further for the Workbook. For example, trucking firms that strongly emphasize safety can achieve a factor of 10 reduction in accident rate (Modern Bulk Transporter 1990); this situation should apply to LANL drivers of hazmat vehicles. Data for SSTs would be similarly applicable and will be sought during workbook preparation. These factors and possibly others could lead to a defensible additional accident rate reduction factor of 5 to 10 . Care must be exercised to assure that double counting does not occur, e.g., the strong safety culture factor of 10 is at least partially included in the third column of Table A-2.

\section{A.2 CONDITIONAL PROBABILITY OF FORCE OCCURRENCE}

Since the distribution of accident types is changed by road closure, the conditional probability of a mechanical force and the conditional probability of a thermal force is also changed. These values will be quantified in the Workbook.

\section{A.3 FORCE MAGNITUDE PROBABILISTIC DISTRIBUTION}

A practical alternative to using the force magnitude curves and tables presented in Section 3.4.2 does not exist. The elimination of long-term fires and high-velocity impact accidents due to administrative controls and the subsequent use of the curves and tables based on general highway conditions for analysis purposes is conservative. 
APPENDIX B

FAULT TREE DEVELOPMENT

$$
\text { B - } 1
$$




\section{APPENDIX B}

\section{FAULT TREE DEVELOPMENT}

A fault tree graphically presents the systematic, logical development of the many causes of an undesirable event. Fault tree analysis begins with the statement of an undesirable event called the top event, for example, "release from transport accident." The next step is to identify the immediate, necessary, and sufficient causes of the top event. Each of the immediate causes is examined in turn to determine its immediate causes. This process continues until the analyst has obtained the desired level of resolution of causes. Each cause can later be assigned probability or frequency values from the available data. The logic symbols shown in Fig. B-1 are used to construct the tree.

To develop a fault tree, the analyst should be aware of the available data and of course the objectives of the analysis. The set of causes for "release from transport accident" might be those shown in Fig. B-2. Each of these three causes could be developed as shown in Fig. B-3 for the impact case.

The sequence of causes for the top event is not unique. For example, the causes of "release from transport accident" could have been stated as (1) release from defective containers, (2) release with human error contribution, and (3) release from accident forces without contributing factors. Each of these three causes would then be developed further. If properly done, this sequence will provide the same end result as the sequence in Figs. B-2 and B-3. 


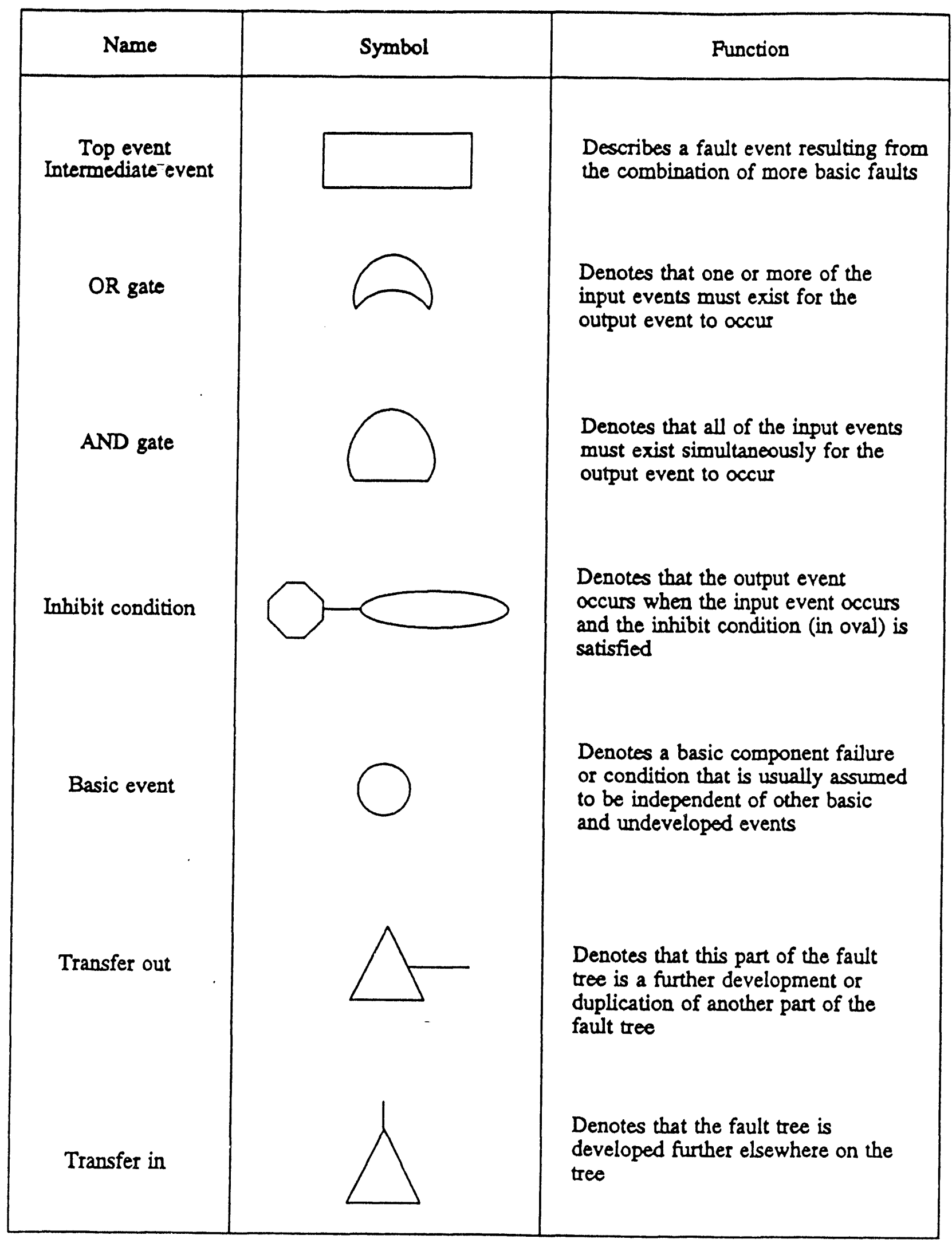

Fig. B-1. Fault tree logic symbols

B - 3 


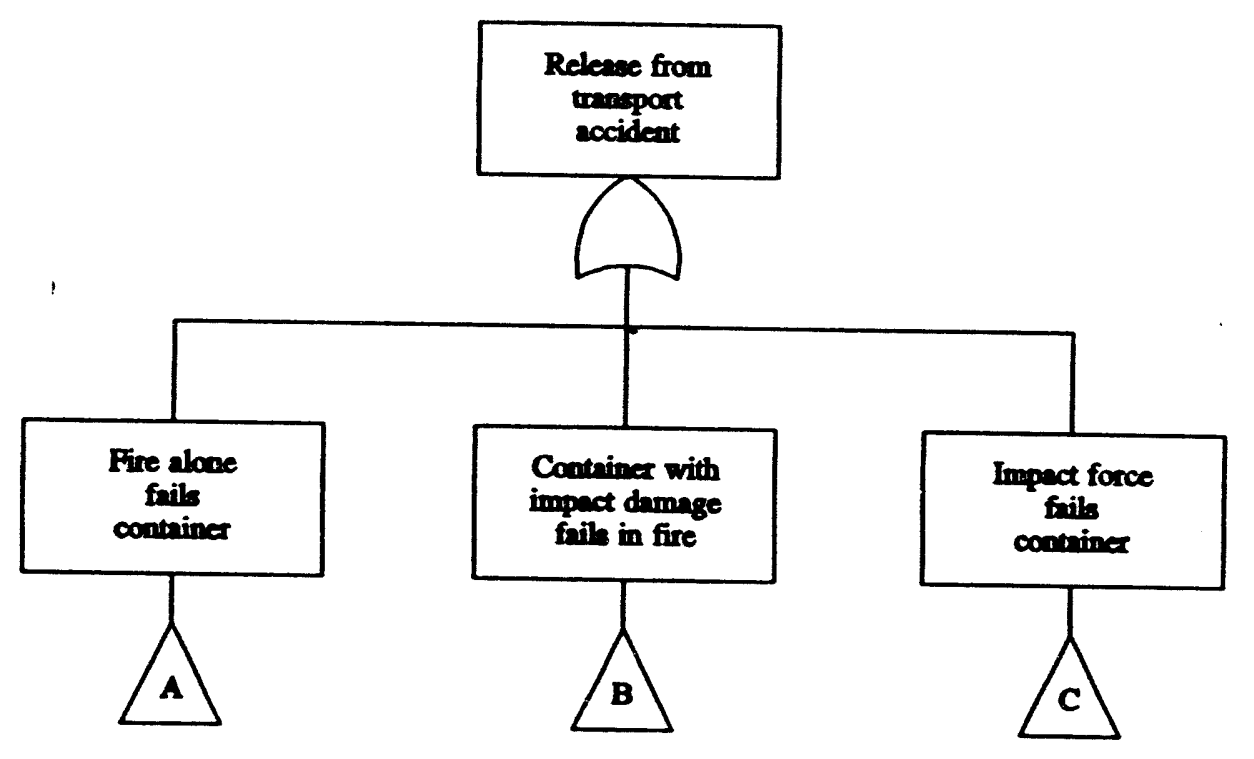

Fig. B-2. Fault tree for release from transport accident

$$
\text { B - } 4
$$




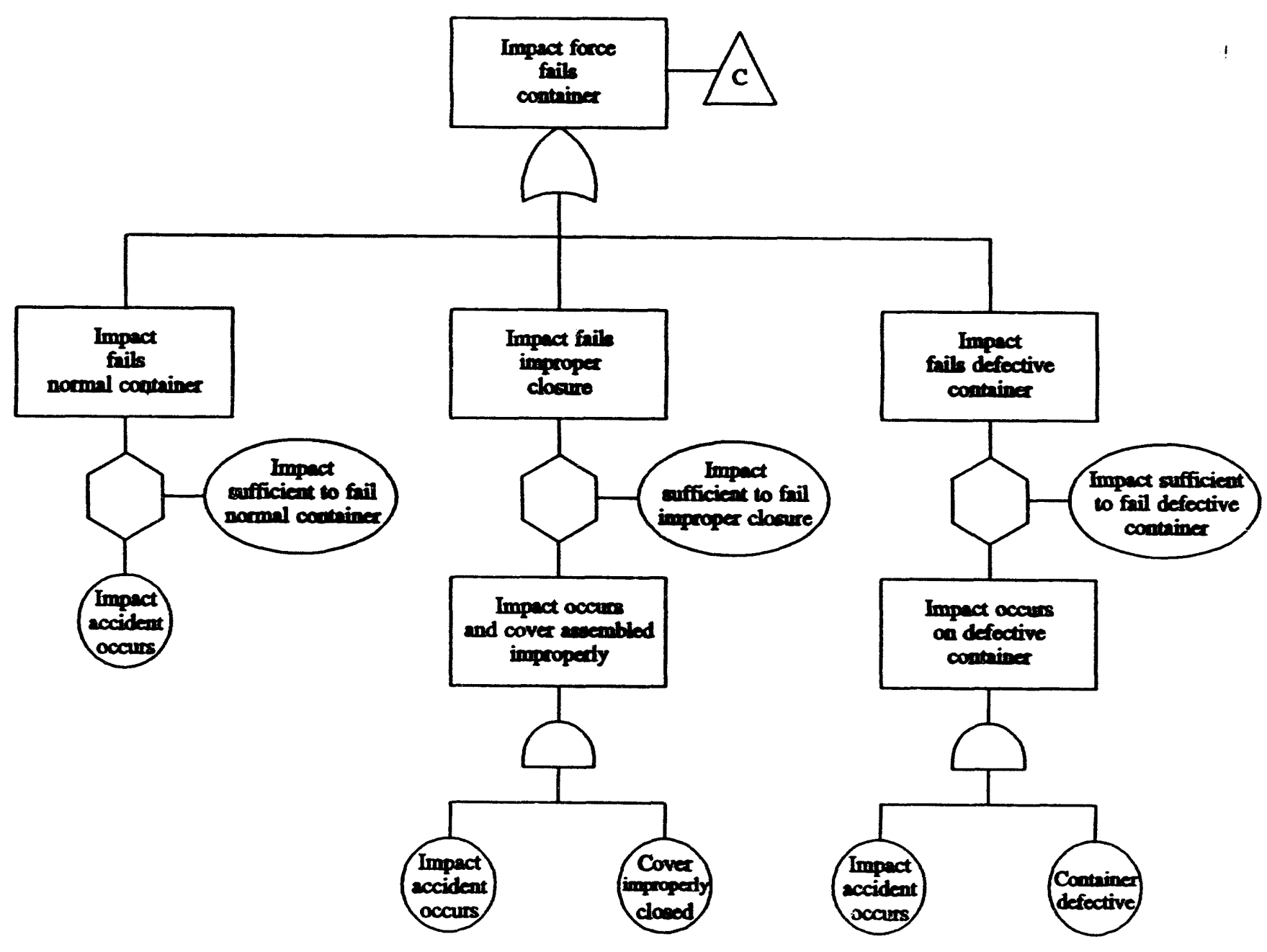

Fig. B-3. Fault tree for impact force fails container

$$
\text { B - } 5
$$


APPENDIX C

EVENT TREE DEVELOPMENT

C - 1 


\section{APPENDIX C}

\section{EVENT TREE DEVELOPMENT}

An event tree is a graphical model for identifying and evaluating outcomes from a specific initiating event. The event tree depicts the chronological sequence of events, i.e., accident scenarios, that could result from the initiating event.

The first step is to identify the initiating event, for example, "accident occurs." The analyst asks what protective system action, operator action, normal system function, and so forth is expected to occur next. Each event following the initial event is conditional on the preceding event. The outcomes of the events are usually binary, i.e., the success or failure of an operator action or alternatively, yes, the safety system functioned, or no, it did not.

To construct the tree, a horizontal line is drawn on the left-hand side of a page and the accident initiator is identified directly above at the top of the sheet (Fig. C-1). The next event is listed at the top and to the right of the initiating event, and the binary outcome of the event is indicated by a branch point that splits the initiating event into two states represented by two horizontal lines. As shown in Fig. C-1, the "mechanical forces occur" condition is the upper branch and the "mechanical forces do not occur" condition is the lower branch. For the top branch only, the "mechanical forces fail container" event applies and the top branch splits. At this point three accident scenarios have been defined. Two branches are for the two container mechanical force scenarios and one branch for a scenario in which no mechanical forces occur.

Fire can occur after events involving mechanical forces. If the container has failed from mechanical forces, the fire can still affect the release characteristics. If mechanical forces have not caused the container to fail, the fire may be of sufficient length to cause the container to fail. The "fire occurs" event does not add new information to the bottom scenario since, by definition, if mechanical forces do not occur then fire forces do. The next event, "thermal forces fail container" do not apply to scenarios in which the container has already failed or in which no fire occurs.

A column is usually added to the event tree after the last event to insert a unique accident sequence descriptor and alpha numeric identifier for later use.

By convention, the event tree is usually arranged so that the outcomes trend from less severe at the top to more severe at the bottom of the outcome column. This convention is

$$
\text { C }-2
$$




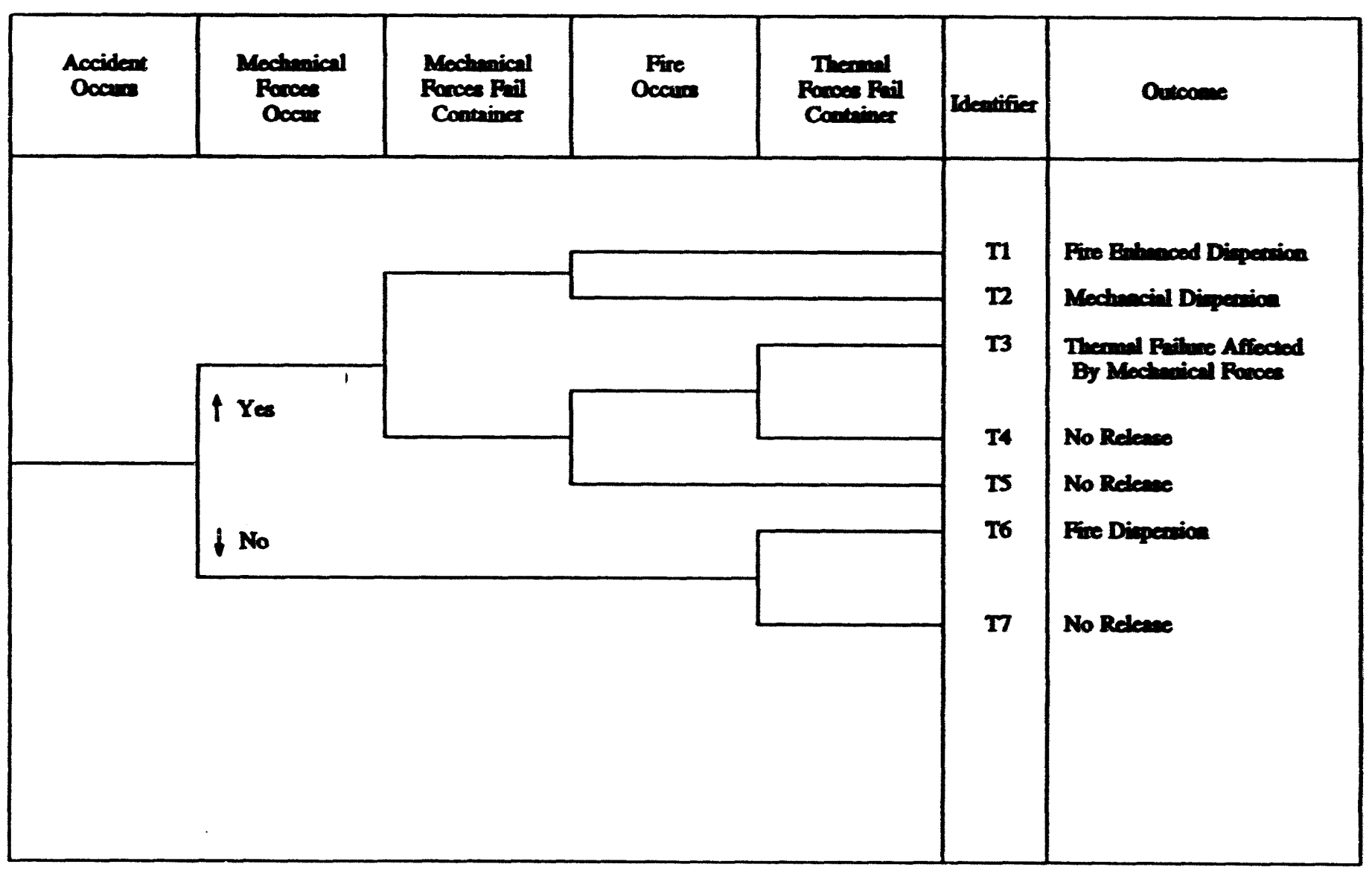

Fig. C-1. Simplified transportation event tree

$$
\text { C - } 3
$$


convenient for developing trees that address the ability of operator actions and active safety systems to prevent the release of hazardous material. Success or "yes" in the upward branching direction will put the most benign outcomes at the top for such events. For passive systems like transport containers, wording the event descriptors to achieve the same ordering of outcomes is frequently awkward. Since the outcomes are all labeled, there is little potential for confusion just because the most benign outcome is at the bottom.

The event tree can be used directly to quantify the frequency of the accident scenario. For example, in Fig. C-2 the accident occurrence frequency is assigned the value $A$, and the probability that mechanical forces occur is assigned the value $B$. Then the probability that mechanical forces do not occur is 1-B. The example is continued by assigning $C$ as the probability that mechanical forces cause the container to fail, $D$ as the probability that fire occurs, and $E$ as the probability that thermal forces cause the container to fail. The frequency of the $T 1$ scenario is the product of $A, B, C$, and $D$, and the frequency of the $T 7$ scenario is the product of $A, 1-B$, and 1-E. Note that the values of $\mathrm{D}$ and $\mathrm{E}$ may be different for the different scenarios.

Fault trees can be used to determine the numerical values to be used in event trees as shown in Fig. C-3. The top event in each fault tree should be the corresponding branch event in the event tree. 


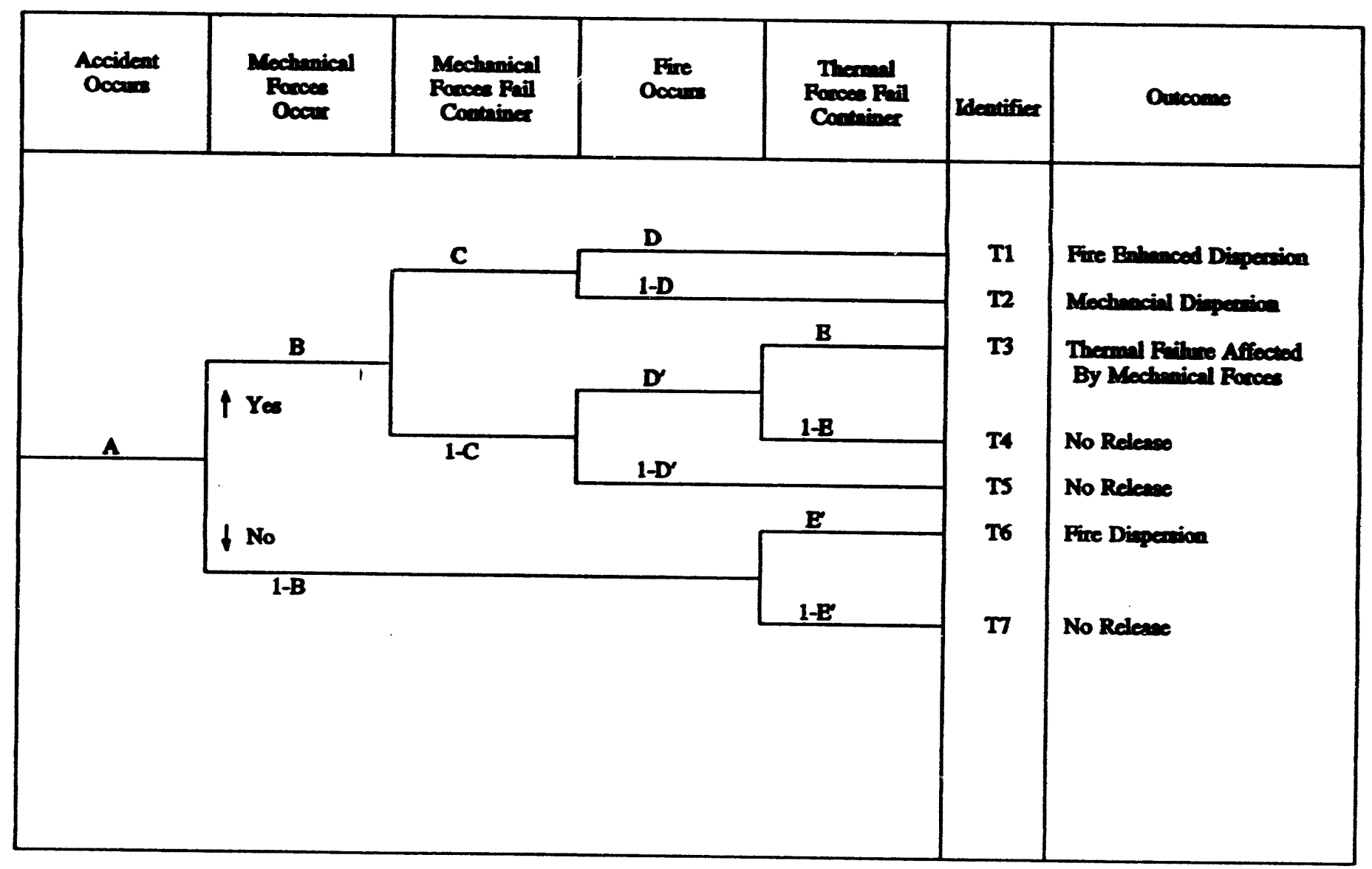

Fig. C-2. Quantified event tree

$$
\text { C - } 5
$$




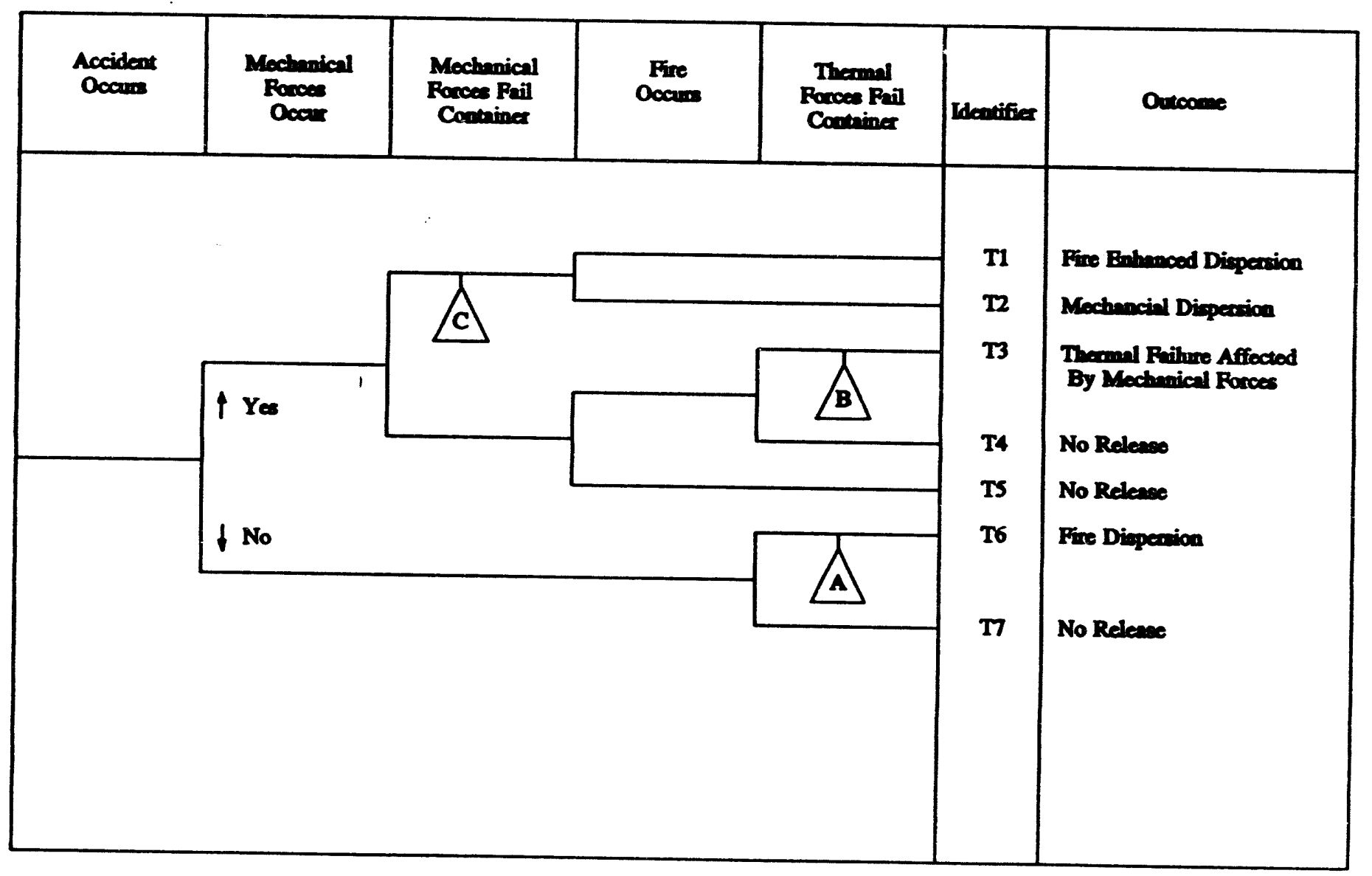

Fig. r.-3. Fault trees used with the event tree

$$
\text { C - } 6
$$



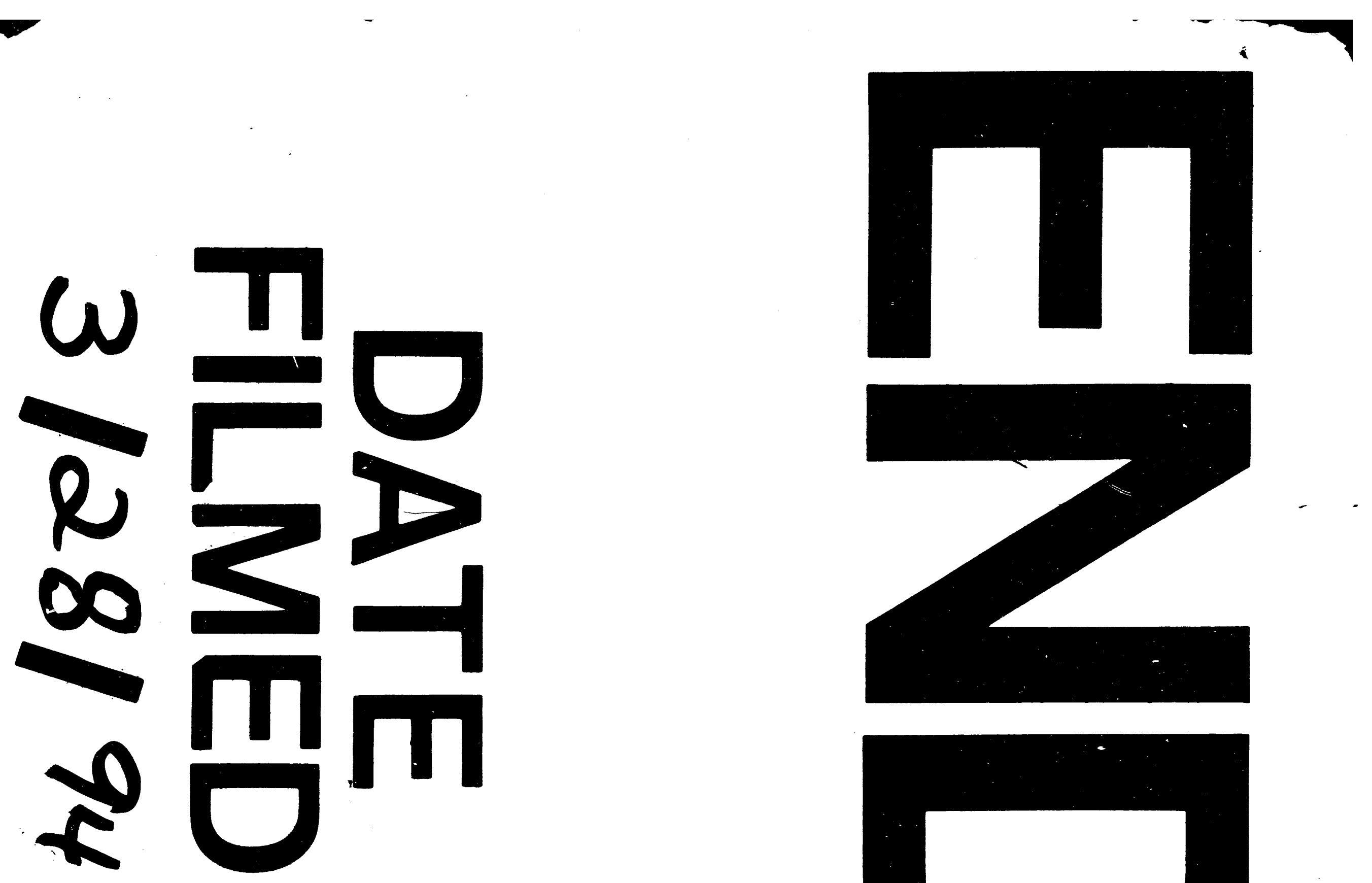
